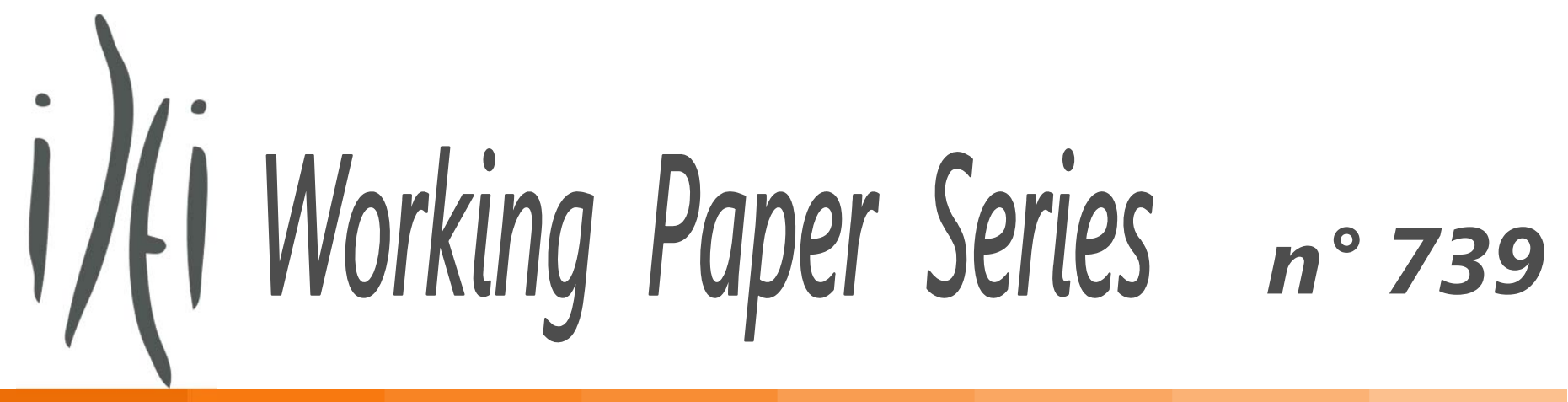

September 2012

\title{
« On the strategic value of risk management »
}

\author{
Thomas-Olivier Léautier \\ and \\ Jean-Charles Rochet
}




\title{
On the strategic value of risk management ${ }^{1}$
}

\author{
Thomas-Olivier Léautier \\ Toulouse School of Economics (IAE, University of Toulouse Capitole) \\ thomas.leautier@iae-toulouse.fr \\ Jean-Charles Rochet \\ University of Zurich and Toulouse School of Economics \\ jean-charles.rochet@bf.uzh.ch
}

Revised Version, September 32012

\footnotetext{
${ }^{1}$ We thank Patrick Rey, Bill Rogerson, Jean Tirole, and participants at the finance and economics seminar at HEC Montréal, at Paris-Dauphine University and at the IDEI/Northwestern 2010 annual conference for their insightful comments. We are also grateful to the editor, Daniel Spulber, and two anonymous referees for carefully reviewing a previous version and providing very useful suggestions.
} 


\begin{abstract}
This article examines how firms facing volatile input prices and holding some degree of market power in their product market link their risk management and production or pricing strategies. This issue is relevant in many industries ranging from manufacturing to energy retailing, where risk averse firms decide on their hedging strategies before their product market strategies. We find that hedging modifies the pricing and production strategies of firms. This strategic effect is channelled through the expected risk-adjusted cost, i.e., the expected marginal cost under the measure induced by investors' risk aversion, and has diametrically opposed impacts depending on the nature of product market competition: hedging toughens quantity competition while it softens price competition. Finally, committing to a hedging strategy is always a best response to non committing, and is a dominant strategy if firms compete à la Hotelling.
\end{abstract}

JEL Classification: L13, G32 


\section{Introduction}

Most of the formal analyses of corporate risk management decisions (for example Froot and Stein (1998), Rochet and Villeneuve (2011), and Bolton, Chen and Wang (2011)) describe a single price-taking firm that faces volatile cash flows and optimizes its mix of reserves (cash or debt capacity) and derivatives instruments (forward and options).

In many instances, this analysis constitutes a valid representation of reality. Firms producing commodities and raw materials (e.g., metals and minerals, oil and gas, electric power) face output price volatility that translates directly into cash flow volatility. In many industries, such as manufacturing, food processing, transportation, and energy retailing, firms face input prices, not output prices, volatility. When firms have no market power in their product market, the single-firm risk management logic applies. Individual hedging demand from these price-taking firms can then be aggregated to determine the equilibrium price of risk (for example, Bessembinber and Lemmon (2002), and Aid et al. (2011)).

If, however, firms facing input price volatility have some degree of market power in their product market, their strategies become more elaborate. For example, a firm can pass through to customers a portion of the input cost increase and/or can retain a portion of the input cost decrease. However, by modifying product price, the firm alters the competitive dynamics in its industry. It must therefore take into account the behavior of other firms, and the pass-through is determined in equilibrium.

The British electric power retailing sector provides a clear example of hedging arising as an equilibrium. The British regulator (Ofgem (2008), page 10) indicates that: "there is evidence that the (6 largest suppliers) seek to benchmark their hedging strategies against each other in order to minimize the risk of their wholesale costs diverging materially from the competition". Private conversations with key participants of the industry confirm that each expands considerable competitive intelligence effort to estimate the others' hedging position. Retailers then play a symmetric Nash equilibrium. What matters to them is not the absolute value of their hedging position, but its value relative to their competitors.

This article examines how hedging interacts with product market strategy when firms compete in quantity (Cournot) and in price (Bertrand differentiated). 
In the economics and finance literature, various authors have developed models where firms jointly determine their hedging ratios as a Nash equilibrium. Closest to this work, Allaz and Villa (1993) examine the interplay of forward and spot markets, and find that the availability of forward contracts reduces firms' market power in the spot market. However, their analysis differs from ours in a critical aspect: in their setting, firms sell their output on the forward or spot markets, where they exert market power, while in ours, firms exert no market power in the spot and forward markets for input. Adam, Dasgupta, and Titman (2007) examine two-period games in the presence of financial constraints: firms' hedging decision in the first-period affect their investment capacity, hence their profitability in the second period. They show that asymmetric equilibria arise: in equilibrium, some firms hedge, while others do not. In their model, the presence of financial constraints and the resulting potential underinvestment is the conduit for strategic interaction. Similarly, Loss (2012) examines the interaction between hedging demand and the strategic characteristics of investment opportunities in the presence of financial constraints. He finds that a firm's hedging demand is high when investments are strategic substitutes, and low when they are strategic complements. In this article's setting, by contrast, pricing and hedging are part of the same strategy. Bodnar, Dumas, and Marston (2002) consider a duopoly with asymmetric exposure to an exchange rate, and determine the optimal pass-through and related exposure. While the problem is related to the one examined here, the analytical approach is very different: they treat exchange rate as a fixed input price, not as a stochastic variable. This article's contribution is therefore to analyze the strategic interactions between product market and hedging decisions of large corporations.

We focus the analysis on risk-averse firms that hedge before deciding their product market strategies. As will be discussed, risk-aversion arises naturally from financial constraints. Hedging is a publicly observable commitment: hedging strategies must be reported to investors, and Board of Directors issue strict hedging guidelines, which prevent risk managers from overturning a position. Many industrial firms commit to their hedging strategy a year in advance, before setting their product market strategy. Formally, we model two-stage games: firms first determine their hedging strategy, then determine their product market strategy, conditional on their first stage choice.

We first analyze quantity competition. The necessary first-order conditions characterizing an equilibrium candidate of the production game are 
similar to the standard Cournot case, except that the expected risk-adjusted cost replaces the marginal cost. Investors value a marginal cost increase using the probability measure induced by their marginal utility of wealth in each state of the world, and not the physical probability measure. This expected risk-adjusted marginal cost is determined in equilibrium. It is decreasing in own hedging, and increasing in own production at the equilibrium. Thus, if a firm increase its hedging, it becomes more aggressive (Lemma 1).

An equilibrium of the production game always exists. If the absolute risk aversion of profits is "weakly" correlated to input cost (this statement is made precise in Section 5), this equilibrium is unique, and an increase in own hedging reduces the other firm's equilibrium output (Proposition 1). If a symmetric equilibrium of the hedging game exists, and absolute risk aversion of profits is "weakly" correlated to input cost, hedging toughens quantity competition: firms hedge more than their (anticipated) equilibrium production, thus commit themselves to produce more than if their costs were constant and equal to the expected cost under the physical probability measure (Proposition 2).

We establish similar results for differentiated price competition; although with diametrically opposed implications. The expected risk-adjusted marginal cost, determined in equilibrium, replaces the constant marginal cost in the necessary first-order conditions characterizing an equilibrium candidate of the pricing game. It is decreasing in own hedging and decreasing in own price at the equilibrium. If a firm increases its hedging, it becomes more aggressive (Lemma 2).

An equilibrium of the pricing game always exists. If absolute risk aversion is constant, the equilibrium is unique, and an increase in own hedging reduces the other firm's equilibrium price. The crucial difference compared to quantity competition is that, if a symmetric equilibrium of the hedging game exists and absolute risk aversion is constant, hedging softens quantity competition: firms hedge less than their (anticipated) equilibrium production, thus commit themselves to a price higher than if their cost was constant equal to the expected cost (Proposition 3).

For ease of exposition, the unicity and comparative statics results when firms compete in quantity are derived using the strong sufficient condition that risk aversion is constant. The weaker sufficient condition that absolute risk aversion of profits is "weakly" correlated to input cost is derived in Propo- 
sition 4. Similarly, a weaker sufficient condition for hedging to soften price competition is presented in Proposition 5.

Finally, we examine the strategic incentives to commit to a hedging position (Proposition 6). Sofar, we have assumed that Boards of Directors impose that firms commit to their hedging position to limit speculation by traders. Ignoring that objective, does commitment arise in equilibrium? We first prove that committing is a firm's the best response to the other not committing. This result is all the more striking that both firms committing is Pareto dominated if firms compete in quantity. On the other hand, if firms compete in price, commitment to a hedging strategy softens price competition. If demand is totally inelastic (Hotelling competition), and absolute risk aversion constant, the expected gain in retail profits more than compensate the volatility increase, and commitment is a dominant strategy. Thus, whether firms compete in quantity or in price, they have a strategic incentive to commit, as well as a risk control objective.

This article is structured as follows: Section 2 presents the model. Section 3 analyzes quantity competition. Section 4 analyzes price competition. Section 5 discusses robustness of the results. Section 6 examines incentives to commit to the hedging strategy. Finally, Section 7 discusses further research. Technical proofs are presented in the Appendix.

\section{The model}

\subsection{Demand and commercial profits}

Consider two symmetric firms, indexed by $i=1,2$, competing à la Cournot. Firm $i$ produces output $q_{i}$, total production is $Q=q_{i}+q_{j}$, and inverse demand $P\left(q_{i}+q_{j}\right)$. To produce one unit of good or service, both firms use one unit of the same input, at cost $\tilde{c}$. Firm $i$ 's commercial profits ${ }^{1}$ for input cost $\tilde{c}$ is:

$$
\pi_{i}^{R}\left(q_{i}, q_{j} ; \tilde{c}\right)=q_{i}(P(Q)-\tilde{c})
$$

Assumption 1 For all $Q \geq 0$, the inverse demand function $P($.$) satisfies$

$$
\frac{Q P^{\prime \prime}(Q)}{\left(-P^{\prime}(Q)\right)}<1
$$

\footnotetext{
${ }^{1}$ Throughout the article, the following - slightly redundant - notation is used: for any function $f(x, y), f_{i}\left(x_{i}, x_{j}\right)$ represents the value of $f()$ for firm $i$ that plays $x_{i}$ (the first argument) while firm $j$ plays $x_{j}$. To simplify the notation, the arguments are sometimes ommitted.
} 
and

$$
\lim _{Q \rightarrow \infty} A(Q)=0 \text { and } \lim _{Q \rightarrow 0} A(Q)=\lim _{Q \rightarrow 0} P(Q)=+\infty
$$

where

$$
A(Q)=2 P(Q)+Q P^{\prime}(Q)
$$

\subsection{Constant input cost}

Before introducing uncertainty, it is useful to briefly review the properties of the equilibrium when input costs are constant and equal to $c_{i}$ for each firm $i$. Firm $i$ 's profit is:

$$
\pi_{i}^{R}\left(q_{i}, q_{j} ; c_{i}\right)=q_{i}\left(P(Q)-c_{i}\right)
$$

Then,

$$
\frac{\partial \pi_{i}^{R}}{\partial q_{i}}=\left(P(Q)-c_{i}\right)+q_{i} P^{\prime}(Q) \text { and } \frac{\partial^{2} \pi_{i}^{R}}{\left(\partial q_{i}\right)^{2}}=2 P^{\prime}(Q)+q_{i} P^{\prime \prime}(Q) .
$$

Condition 1 guarantees that $\frac{\partial^{2} \pi_{i}^{R}}{\left(\partial q_{i}\right)^{2}}<0$. Thus, if a Cournot equilibrium exists, it is characterized by the necessary first-order conditions:

$$
\frac{\partial \pi_{i}^{R}}{\partial q_{i}}=\left(P(Q)-c_{i}\right)+q_{i} P^{\prime}(Q)=0
$$

Assumption 1 guarantees that, for all $c>0$,

$$
A(Q)=2 P(Q)+Q P^{\prime}(Q)=c
$$

admits a unique solution $Q^{E}(c)$. We further assume that

$$
\left|c_{j}-c_{i}\right|<\min \left(\left|\frac{D\left(c_{i}\right)}{D^{\prime}\left(c_{i}\right)}\right|,\left|\frac{D\left(c_{j}\right)}{D^{\prime}\left(c_{j}\right)}\right|\right),
$$

where $D($.$) is the demand function induced by P($.$) . This eliminates possible$ corner equilibria (e.g., $q_{1}=0, q_{2}>0$ ). Then, the equilibrium quantities are:

$$
q_{i}^{E}\left(c_{1}, c_{2}\right)=\frac{P\left(Q^{E}\left(c_{1}+c_{2}\right)\right)-c_{i}}{\left(-P^{\prime}\left(Q^{E}\left(c_{1}+c_{2}\right)\right)\right)}
$$

Finally, we verify in Appendix A that:

$$
\frac{\partial q_{i}^{E}}{\partial c_{i}}=\frac{2 P^{\prime}\left(Q^{E}\right)+q_{j}^{E} P^{\prime \prime}\left(Q^{E}\right)}{P^{\prime}\left(Q^{E}\right)\left(3 P^{\prime}\left(Q^{E}\right)+Q^{E} P^{\prime \prime}\left(Q^{E}\right)\right)}<0
$$


and

$$
\frac{\partial q_{i}^{E}}{\partial c_{j}}=-\frac{P^{\prime}\left(Q^{E}\right)+q_{i}^{E} P^{\prime \prime}\left(Q^{E}\right)}{P^{\prime}\left(Q^{E}\right)\left(3 P^{\prime}\left(Q^{E}\right)+Q^{E} P^{\prime \prime}\left(Q^{E}\right)\right)}>0 .
$$

\subsection{Uncertainty on input costs and risk management}

We return to the random input cost case. Ex ante, the input cost $\tilde{c}$ is a random variable, distributed following cumulative distribution function $G$ (.) on bounded support $\Omega=[\underline{c}, \bar{c}]$. $\Omega$ and $G($.$) are common knowledge to both$ firms.

Firms can purchase input in the wholesale forward market at (forward) price $F$. To eliminate speculative motives for hedging, we assume that $F=$ $\mathbb{E}[\tilde{c}]$ and does not change over time. There are no transaction costs associated with hedging.

Firms do not exert market power in the spot and forward wholesale markets for input, even though they do exert market power in their product market. For example, airlines do not exert market power in the fuel market, yet they are an oligopoly on specific routes (see for example Gerardi and Shapiro (2009)); food processing firms may not exert market power in the feedstock market, while most empirical studies document market power in their product markets (see for example Sheldon and Sperling's (2001) survey).

\subsection{Three empirically relevant timings}

Three distinct timings are observed, that depend on the timing of the production decision:

1. Production then hedging: the firms first decide on their production at $t=0$, then on their hedging strategy at $t=1$. Finally, input cost and profits are realized at $t=2$.

2. Hedging then production: the firms first decide on their hedging strategy at $t=0$, then on their production $t=1$, before input cost and profits are realized at $t=2$.

3. Flexible production after input cost known: the firms decide on their hedging strategy at $t=0$, then on their production strategy at $t=2$ after input cost is realized at $t=1$. Finally, profits are realized.

Since $F$ is constant, hedging before or after production does not modify the (expected) gains. 
Timings 1 and 2 are relevant for most manufacturing industries: producers (e.g., car manufacturers) commit to a product price or volume for the relevant period (typically one or two quarters). During that period, input prices (e.g., aluminum and steel prices) vary. These timings are also relevant for the retail power industry in Britain, where retail rates typically change only 3 or 4 times a year, while wholesale power prices vary continuously. This price inflexibility could be due for example to the high cost of adjusting prices, or simply to industry practices. We take this inflexibility as given in this article, leaving its endogeneization to further work.

Timing 3 applies to industries where output price is flexible. For example delivery services (e.g., Fedex and UPS) explicitly include in their published rate a fuel surcharge schedule, that depends on the price of an oil index. Similarly, electricity retailers in Norway offer retail contracts explicitly adjusted to the wholesale power price.

Timings 2 and 3 represent two-stage games, where the hedging decision is made first, followed by the production decision. For a strategic interaction to arise $(i)$ industrial firms' hedging decisions must be public knowledge, and (ii) industrial firms must have the possibility to commit to their hedging strategy. We now justify both assumptions.

First, financial regulations require firms to publish in their quarterly statements a description of their portfolio of forward purchases and sales. While some discretion still exists in disclosure, an outside party can get a close picture of a firm's hedging portfolio. For example, Jin and Jorion (2007) were able to compute the delta-equivalent of the forward portfolio for US oil and gas companies, and, as previously mentioned, electricity retailers in Britain infer each other's hedging portfolio from financial statements and other public information.

Second, industrial firms can - and in practice do - commit to a hedging strategy through their risk management policy. Forward sales and purchases, that require the use of derivatives, are usually handled with extreme caution by Board of Directors, concerned about potential speculative behavior by traders. Boards then require management to define and follow a clear hedging strategy, often declining in time: for example "hedge fully our exposure for the next quarter, hedge half of the exposure for the next two quarters, and a fourth of our exposure for the quarter after". As mentioned earlier, this strategy is communicated to investors and regulators. Management has then limited discretion to deviate from this strategy. 
Our first observation is that no strategic interaction arises under timings 1 and 3, i.e., there exists a dichotomy between hedging and production.

Consider first timing 1: firms select output, then hedge. Reasoning backwards, consider first the hedging decision, once production is known. Since (i) firms are risk averse, and (ii) there are no transaction costs nor expected gain from hedging (i.e., $\mathbb{E}[\tilde{c}]-F=0$ ), full hedging is the optimal strategy. Consider now the production decision. Knowing that input costs will be perfectly covered at the forward price, firms play a symmetric Cournot game with constant marginal costs equal to $F$, thus their equilibrium output is $q^{E}(F, F)$.

Consider now timing 3: firms set production after the input price is realized. The profit from the hedge is known before the production decision is made, thus has no impact on it. Firms cannot do any better than standard deterministic profit maximization. Knowing that, when firms make the hedging decision, they follow the "standard" one-firm risk management logic.

Thus, this article if focussed on situations where risk-averse firms hedge before making their production decision.

\subsection{Objective function}

At $t=2$ (i.e., once the input cost $\tilde{c}$ is known), the profit function of firm $i$ that has purchased forward quantity $H_{i}$ at the forward price $F$ is:

$$
\begin{aligned}
\pi_{i}\left(q_{i}, q_{j}, H_{i} ; \tilde{c}\right) & =q_{i}(P(Q)-\tilde{c})+H_{i}(\tilde{c}-F) \\
& =q_{i}(P(Q)-F)+\left(H_{i}-q_{i}\right)(\tilde{c}-F) .
\end{aligned}
$$

The first expression of firm $i$ 's profits reflects a purchase of input volume $q_{i}$ at cost $\tilde{c}$, and profit $(\tilde{c}-F)$ on the volume $H_{i}$ purchased forward at $t=0$. Alternatively, the firm can consider its production cost is $F$, and that its exposition to input price fluctuations is $\left(H_{i}-q_{i}\right)$.

We assume that firms maximize some expected utility of profits $U\left(\pi_{i}\right)$ where $U($.$) is increasing and (weakly) concave. To obtain a strategic impact$ of risk management, a crucial ingredient is that firms are risk-averse. There are several possible reasons for this assumption. In the case of small firm, owned and managed by the same person, the objective of this owner-manager is to maximize the expected utility of her wealth, the profit of the firm being a large component of this wealth. 
However, we are mostly interested in large firms, typically owned by a diffuse population of small shareholders, and whose managers own only a small fraction of the shares. If managers act in the best interest of diversified shareholders and the stock market is frictionless, the objective should be to maximize the expected present value of future profits, where the expectation is taken under the risk adjusted distribution, which incorporates risk premia. Such a framework is consistent with the Modigliani and Miller theorems, and implies in particular that corporate risk management does not create any value for shareholders.

A more realistic description of reality incorporates financial frictions, typically in the form of a wedge between the costs of external and internal finance (Froot, Scharfstein, and Stein (1993)), transaction costs of primary security markets (Décamps et al. (2011)), or agency costs (DeMarzo and Sannikov (2006), Biais et al. (2007)). In each of cases, shareholder value (once firms optimize their financing and investment policies) can be represented as the expectation of a concave function of future profits. Even when shareholders are risk neutral (or completely diversified), financial frictions generate risk aversion in the (indirect) preferences of shareholders.

It is thus legitimate for us to represent these shareholders' preferences by a concave function of future profits, denoted $U(\pi)$. For simplicity, we consider a symmetric model where $U($.$) is the same for all firms. We do not attempt to$ endogenize $U$ (.) by modelling explicitly the financial frictions and the optimal financing and investment policies that give rise to this function $U($.$) .$

Consistent with the literature reviewed above, we further assume that absolute risk aversion $\rho(\pi)=\left(-\frac{U^{\prime \prime}}{U^{\prime}}\right)(\pi)$ is non-increasing.

At date $t=0$, the shareholder value of firm $i$ is then:

$$
\begin{aligned}
v_{i}\left(q_{i}, q_{j}, H_{i}\right) & =\mathbb{E}\left[U\left(\pi_{i}\left(q_{i}, q_{j}, H_{i} ; \tilde{c}\right)\right)\right] \\
& =\mathbb{E}\left[U\left(q_{i}(P(Q)-F)+\left(H_{i}-q_{i}\right)(\tilde{c}-F)\right)\right]
\end{aligned}
$$

We look for subgame perfect equilibria of the two-stage games played by firms. We solve by backward induction: we first determine the unique the second-stage equilibrium $\left(q_{i}^{*}\left(H_{i}, H_{j}\right), q_{j}^{*}\left(H_{i}, H_{j}\right)\right)$, then insert its value into $v_{i}$ to obtain the first-stage payoff functions, denoted $V_{i}\left(H_{i}, H_{j}\right)$. 


\section{Over-hedging to commit to higher output}

\subsection{Random input costs: an illustrative example}

Before solving the general case, we illustrate the main insights using a simple example: (i) absolute risk aversion is constant, which yields $U(x)=1-$ $\exp (-x),(i i)$ inverse demand is linear $P(Q)=1-Q$, and (iii) input cost $\tilde{c}$ is normally distributed ${ }^{2}$, with mean $F$ and standard deviation $\sigma$.

$$
\begin{aligned}
v_{i}\left(q_{i}, q_{j}, H_{i}\right) & =\mathbb{E}\left[1-\exp \left(-\rho\left(q_{i}(P(Q)-F)+\left(H_{i}-q_{i}\right)(\tilde{c}-F)\right)\right)\right] \\
& =1-\exp \left(-\rho m_{i}\left(q_{i}, q_{j}, H_{i}\right)\right)
\end{aligned}
$$

where

$$
\begin{gathered}
m_{i}\left(q_{i}, q_{j}, H_{i}\right)=q_{i}(P(Q)-F)-\frac{\rho\left(H_{i}-q_{i}\right)^{2} \sigma^{2}}{2} . \\
\frac{\partial v_{i}\left(q_{i}, q_{j}, H_{i}\right)}{\partial q_{i}}=\rho \exp \left(-\rho m_{i}\left(q_{i}, q_{j}, H_{i}\right)\right) \frac{\partial m_{i}}{\partial q_{i}} \\
=\rho \exp \left(-\rho m_{i}\right)\left(P(Q)-F+q_{i} P^{\prime}(Q)+\rho \sigma^{2}\left(H_{i}-q_{i}\right)\right)
\end{gathered}
$$

and

$$
\frac{\partial^{2} v_{i}\left(q_{i}, q_{j}, H_{i}\right)}{\left(\partial q_{i}\right)^{2}}=\rho \exp \left(-\rho m_{i}\left(q_{i}, q_{j}, H_{i}\right)\right)\left(\frac{\partial^{2} m_{i}}{\left(\partial q_{i}\right)^{2}}-\rho\left(\frac{\partial m_{i}}{\partial q_{i}}\right)^{2}\right)<0
$$

since

$$
\frac{\partial^{2} m_{i}}{\left(\partial q_{i}\right)^{2}}=2 P^{\prime}(Q)+q_{i} P^{\prime \prime}(Q)-\rho \sigma^{2}<0 .
$$

Replacing $P(Q)$ by its expression, the first-order necessary and sufficient conditions characterizing the equilibrium are

$$
q_{i}\left(2+\rho \sigma^{2}\right)+q_{j}=1-F+\rho \sigma^{2} H_{i}
$$

for $i=1,2$, which yield the equilibrium

$$
q_{i}^{*}\left(H_{i}, H_{j}\right)=\frac{1}{3+\rho \sigma^{2}}\left(1-F+\frac{\rho \sigma^{2}}{1+\rho \sigma^{2}}\left(\left(2+\rho \sigma^{2}\right) H_{i}-H_{j}\right)\right)
$$

\footnotetext{
${ }^{2}$ The support of the distribution of cost is not bounded. However, as we will prove below, the main results still hold.
} 
for $i=1,2$.

$$
V_{i}\left(H_{i}, H_{j}\right)=1-\exp \left(-\rho m_{i}\left(q_{i}^{*}\left(H_{i}, H_{j}\right), q_{j}^{*}\left(H_{i}, H_{j}\right), H_{i}\right)\right)
$$

Thus,

$$
\begin{aligned}
\frac{\partial V_{i}}{\partial H_{i}} & =\rho \exp \left(-\rho m_{i}\left(q_{i}^{*}, q_{j}^{*}, H_{i}\right)\right)\left(\frac{\partial m_{i}}{\partial q_{i}} \frac{\partial q_{i}^{*}}{\partial H_{i}}+\frac{\partial m_{i}}{\partial q_{j}} \frac{\partial q_{j}^{*}}{\partial H_{i}}+\frac{\partial m_{i}}{\partial H_{i}}\right) \\
& =\rho \exp \left(-\rho m_{i}\left(q_{i}^{*}, q_{j}^{*}, H_{i}\right)\right)\left(q_{i}^{*} P^{\prime}(Q) \frac{\partial q_{j}^{*}}{\partial H_{i}}-\left(H_{i}-q_{i}^{*}\right) \rho \sigma^{2}\right) \\
& =-\rho^{2} \sigma^{2} \exp \left(-\rho m_{i}\left(q_{i}^{*}, q_{j}^{*}, H_{i}\right)\right)\left(H_{i}-\left(1+\frac{1}{\left(3+\rho \sigma^{2}\right)\left(1+\rho \sigma^{2}\right)}\right) q_{i}^{*}\right) .
\end{aligned}
$$

The necessary first-order conditions are then:

$$
H_{i}^{*}=\left(1+\frac{1}{\left(3+\rho \sigma^{2}\right)\left(1+\rho \sigma^{2}\right)}\right) q_{i}^{*}
$$

We verify that $\frac{\partial^{2} V_{i}}{\partial^{2} H_{i}}\left(H_{i}^{*}, H_{j}^{*}\right)<0$, hence $\left(H^{*}, H^{*}\right)$ is indeed an equilibrium. Replacing $q_{i}^{*}$ by $q_{i}^{*}\left(H_{i}, H_{j}\right)$ and solving for a symmetric equilibrium yields:

$$
H^{*}=\frac{1+\frac{1}{\left(3+\rho \sigma^{2}\right)\left(1+\rho \sigma^{2}\right)}}{1-\frac{\rho \sigma^{2}}{3\left(3+\rho \sigma^{2}\right)\left(1+\rho \sigma^{2}\right)}} q^{E}(F, F) .
$$

where

$$
q^{E}(F, F)=\frac{1-F}{3}
$$

is the unique symmetric equilibrium output if marginal cost is constant and equal to $F$. Equilibrium output is then:

$$
q^{*}=\frac{1}{1-\frac{\rho \sigma^{2}}{3\left(3+\rho \sigma^{2}\right)\left(1+\rho \sigma^{2}\right)}} q^{E}(F, F)>q^{E}(F, F) .
$$

A few features of the analysis are worth noting. First, $v_{i}\left(q_{i}, q_{j}, H_{i}\right)$ is concave in $q_{i}$, due to the concavity of the profit function $\pi_{i}^{R}$ and the risk aversion.

Second, the first order conditions (4) can be rewritten as

$$
2 q_{i}+q_{j}=1-c_{i}\left(q_{i}, H_{i}\right)
$$


where

$$
c_{i}\left(q_{i}, H_{i}\right)=\left(F+\rho \sigma^{2}\left(q_{i}-H_{i}\right)\right)
$$

is the "risk adjusted" marginal cost, increasing in $q_{i}$, decreasing in $H_{i}$, and lower than the expected cost $F$ if and only if $H_{i}>q_{i}$. Equilibrium of the production game is the solution of the system:

$$
\left\{\begin{array}{l}
q_{1}=q_{1}^{E}\left(c_{1}\left(q_{1}, H_{1}\right), c_{2}\left(q_{2}, H_{2}\right)\right) \\
q_{2}=q_{1}^{E}\left(c_{1}\left(q_{1}, H_{1}\right), c_{2}\left(q_{2}, H_{2}\right)\right)
\end{array} .\right.
$$

Finally, at the equilibrium, firms hedge more than they will produce, i.e., $H^{*}>q^{*}$, which yields a risk-adjusted cost lower than $F$. Thus, firms produce more than if costs were $F: q^{*}>q^{E}(F, F)$. Random input costs lead to higher input and lower equilibrium price.

As we will see in the remainder of this article, these features also hold under more general conditions on utility, demand, and input cost distribution.

\subsection{Equilibrium of the production game}

Consider now a general specification.

$$
\begin{aligned}
\frac{\partial v_{i}\left(q_{i}, q_{j}, H_{i}\right)}{\partial q_{i}} & =\mathbb{E}\left[U^{\prime}\left(\pi_{i}\right) \frac{\partial \pi_{i}}{\partial q_{i}}\right] \\
& =\mathbb{E}\left[U^{\prime}\left(\pi_{i}\right)\left(P(Q)-F+q_{i} P^{\prime}(Q)-(\tilde{c}-F)\right)\right] \\
& =\mathbb{E}\left[U^{\prime}\left(\pi_{i}\right)\right]\left(P(Q)+q_{i} P^{\prime}(Q)\right)-\mathbb{E}\left[U^{\prime}\left(\pi_{i}\right) \tilde{c}\right] \\
& =\mathbb{E}\left[U^{\prime}\left(\pi_{i}\right)\right]\left(P(Q)+q_{i} P^{\prime}(Q)-c_{i}\left(q_{i}, q_{j}, H_{i}\right)\right)
\end{aligned}
$$

where

$$
c_{i}\left(q_{i}, q_{j}, H_{i}\right)=\frac{\mathbb{E}\left[U^{\prime}\left(\pi_{i}\left(q_{i}, q_{j}, H_{i}\right)\right) \tilde{c}\right]}{\mathbb{E}\left[U^{\prime}\left(\pi_{i}\left(q_{i}, q_{j}, H_{i}\right)\right)\right]}=F+\frac{\operatorname{cov}\left[U^{\prime}\left(\pi_{i}\left(q_{i}, q_{j}, H_{i}\right)\right), \tilde{c}\right]}{\mathbb{E}\left[U^{\prime}\left(\pi_{i}\left(q_{i}, q_{j}, H_{i}\right)\right)\right]}
$$

is the expected risk-adjusted cost, and

$$
\frac{\partial^{2} v_{i}\left(q_{i}, q_{j}, H_{i}\right)}{\left(\partial q_{i}\right)^{2}}=\mathbb{E}\left[U^{\prime \prime}\left(\pi_{i}\right)\left(\frac{\partial \pi_{i}}{\partial q_{i}}\right)^{2}+U^{\prime}\left(\pi_{i}\right) \frac{\partial^{2} \pi_{i}}{\left(\partial q_{i}\right)^{2}}\right]<0 .
$$

Since $v_{i}\left(q_{i}, q_{j}, H_{i}\right)$ is concave in $q_{i}$, if an interior Nash equilibrium exists, it is determined by the first order conditions

$$
P(Q)+q_{i} P^{\prime}(Q)-c_{i}\left(q_{i}, q_{j}, H_{i}\right)=0
$$


for $i=1,2$.

Before proving existence of a Nash equilibrium and deriving sufficient conditions for unicity, we examine equation (6). The interaction between hedging and production is channelled through the expected risk-adjusted cost $c_{i}\left(q_{i}, q_{j}, H_{i}\right)$, determined in equilibrium. If the firm produces one more unit, it costs $\tilde{c}$ in each state of the world. Investors value marginal cost using the probability measure induced by their marginal utility of wealth $U^{\prime}\left(\pi_{i}\right)$ in each state of the world, and not according to the physical probability measure. From an investors' perspective, the risk-adjusted expectation of any random variable $x(\tilde{c})$ is:

$$
\widehat{\mathbb{E}}[x(\tilde{c})]=\frac{\mathbb{E}\left[U^{\prime}\left(\pi_{i}\left(q_{i}, q_{j}, H_{i}\right)\right) x(\tilde{c})\right]}{\mathbb{E}\left[U^{\prime}\left(\pi_{i}\left(q_{i}, q_{j}, H_{i}\right)\right)\right]} .
$$

The impact of $q_{i}, q_{j}$, and $H_{i}$ on the expected risk-adjusted cost is summarized in the following Lemma, proven in Appendix A:

Lemma 1 For $\left(q_{i}, q_{j}, H_{i}\right)$ :

$$
\begin{gathered}
\frac{\partial c_{i}}{\partial H_{i}}\left(q_{i}, q_{j}, H_{i}\right)<0 \text { and } c_{i}\left(q_{i}, q_{j}, H_{i}\right) \leq F \Leftrightarrow H_{i} \geq q_{i} . \\
\frac{\partial c_{i}}{\partial q_{j}}\left(q_{i}, q_{j}, H_{i}\right)=-q_{i} P^{\prime}(Q) \widehat{\operatorname{cov}}\left[\rho\left(\pi_{i}\right), \tilde{c}\right]
\end{gathered}
$$

Thus:

$$
\left\{\begin{array}{cc}
\frac{\partial c_{i}}{\partial q_{j}}\left(q_{i}^{*}, q_{j}^{*}, H_{i}\right)=0 \quad \text { if } \rho\left(\pi_{i}\right) \text { constant } \\
\frac{\partial c_{i}}{\partial q_{j}}\left(q_{i}^{*}, q_{j}^{*}, H_{i}\right)<0 \Leftrightarrow H_{i}>q_{i}^{*} \quad \text { otherwise }
\end{array}\right.
$$

For any $\left(H_{i}, H_{j}\right)$ :

$$
\frac{\partial c_{i}}{\partial q_{i}}\left(q_{i}^{*}, q_{j}^{*}, H_{i}\right)>0
$$

A marginal increase in hedging increases the marginal profit from higher input cost. However, this favorable realization is weighted by a lower marginal utility, hence the risk-adjusted expected cost decreases. Thus, "ceteris paribus" increasing $H_{i}$ reduces firm $i$ expected risk-adjusted marginal cost.

Dependency of $c_{i}$ with respect to $q_{i}$ and $q_{j}$ is indirect, channelled through the marginal utility of profits. If absolute risk-aversion is constant, $c_{i}$ depends only on $q_{i}$ and $H_{i}$, which yields a more familiar Cournot game. Otherwise, the impact of $q_{j}$ on $c_{i}$ cannot be signed, that depend on the sign of $\left(H_{i}-q_{i}^{*}\right)$. At the equilibrium output, expected risk-adjusted marginal cost is increasing. 
We now turn to existence and unicity of the equilibrium. Since we ultimately focus on symmetric equilibria, $H_{i}^{*}=H_{j}^{*}=H, q_{i}^{*}=q_{j}^{*}=q^{*}, c_{i}=c_{j}$, we assume that $H_{i}$ and $H_{j}$ are "close enough" that $c_{i}$ and $c_{j}$ satisfy condition (3), and the equilibrium of the production game is interior.

$\left(q_{i}^{*}\left(H_{i}, H_{j}\right), q_{j}^{*}\left(H_{i}, H_{j}\right)\right)$ is thus a fixed point of the system:

$$
\left\{\begin{array}{l}
q_{1}=q^{E}\left(c_{1}\left(q_{1}, q_{2}, H_{1}\right), c_{2}\left(q_{2}, q_{1}, H_{2}\right)\right) \\
q_{2}=q^{E}\left(c_{1}\left(q_{1}, q_{2}, H_{1}\right), c_{2}\left(q_{2}, q_{1}, H_{2}\right)\right)
\end{array} .\right.
$$

Proposition 1 For any $\left(H_{i}, H_{j}\right)$ "close enough", an equilibrium of the production game exists. If absolute risk aversion is constant, the equilibrium is unique, and a marginal increase in firm i's hedging reduces firm j's equilibrium output:

$$
\frac{\partial q_{j}^{*}}{\partial H_{i}}\left(H_{i}, H_{j}\right)<0
$$

Proof.

$\widetilde{c} \leq \bar{c} \Rightarrow c_{i}\left(q_{i}, q_{j}, H_{i}\right) \leq \bar{c} \Rightarrow q_{i}^{E}\left(c_{i}\left(q_{i}, q_{j}, H_{i}\right), c_{j}\left(q_{i}, q_{j}, H_{j}\right)\right) \leq q_{i}^{E}(0, \bar{c})=\bar{q}^{E}$.

Thus, we can limit our search to $\left(q_{i}, q_{j}\right) \in\left[0, \bar{q}^{E}\right]^{2}$. Since $q^{E}(x, y)$ and $c(x, y, z)$ are continuous in all their arguments, and defined on a compact and convex set of $\mathbb{R}^{2}$, Brouwer theorem guarantees existence of an equilibrium.

If absolute risk aversion is constant, we prove in Appendix A that the real part of the eigenvalues of the Jacobian matrix

$$
J\left(q_{1}^{*}, q_{2}^{*}, H_{1}, H_{2}\right)=\left[\begin{array}{cc}
\frac{\partial q_{1}^{E}}{\partial q_{1}}-1 & \frac{\partial q_{1}^{E}}{\partial q_{2}} \\
\frac{\partial q_{2}^{E}}{\partial c_{1}} & \frac{\partial q_{2}^{E}}{\partial q_{2}}-1
\end{array}\right]
$$

are negative, thus the equilibrium is unique. Finally, constant risk aversion implies $\frac{\partial c_{i}}{\partial q_{j}}\left(q_{i}^{*}, q_{j}^{*}, H_{i}\right)=0$ by Lemma 1. Firms play a familiar Cournot game with marginal costs $c_{i}\left(q_{i}, H_{i}\right)$ increasing in $q_{i}$ at the equilibrium, and decreasing in $H_{i}$. We prove in Appendix A that, since increasing hedging reduces a firm's cost, it make her more aggressive, and reduces her competitor's output.

A marginal increase in $H_{i}$ commits firm $i$ to a higher output. This strategic effect can be understood using three equivalent logics. A first logic is that a marginal increase in $H_{i}$ reduces $q_{j}^{*}$, thus increases $q_{i}^{*}$ since quantities are strategic substitutes. A second logic is that a marginal increase in $H_{i}$ 
reduces the risk-adjusted cost, thus increases $q_{i}^{*}$. A final logic is that a marginal increase in $H_{i}$ increases the volume exposed to input price fluctuations $\left(H_{i}-q_{i}\right)$, thus firm $i$ must increase $q_{i}$ to reduce this exposure.

\subsection{Equilibrium of the hedging game}

Suppose a symmetric interior equilibrium of the hedging game $\left(H^{*}, H^{*}\right)$ exists.

Proposition 2 1. The equilibrium is characterized by the necessary firstorder conditions:

$$
\left(c_{i}\left(q^{*}, q^{*}, H^{*}\right)-F+P^{\prime}\left(Q^{*}\right) q_{i}^{*} \frac{\partial q_{j}^{*}}{\partial H_{i}}\right)\left(H^{*}, H^{*}\right)=0
$$

for $i=1,2$.

2. If absolute risk aversion is constant, hedging toughens quantity competition: firms over-hedge thus commit to higher equilibrium output than if marginal costs were constant equal to $F$

$$
H^{*}>q^{*} \Leftrightarrow c_{i}\left(q^{*}, q^{*}, H^{*}\right)<F \Leftrightarrow q^{*}>q^{E}(F, F) .
$$

\section{Proof.}

1. For $i=1,2$, the first-order conditions defining equilibrium hedging volume $H_{i}^{*}$ are:

$$
\mathbb{E}\left[U^{\prime}\left(\pi_{i}\right)\left(\frac{\partial \pi_{i}}{\partial q_{i}} \frac{\partial q_{i}^{*}}{\partial H_{i}}+\frac{\partial \pi_{i}}{\partial q_{j}} \frac{\partial q_{j}^{*}}{\partial H_{i}}+\frac{\partial \pi_{i}}{\partial H_{i}}\right)\right]\left(q_{i}^{*}, q_{j}^{*}, H_{i}^{*}\right)=0 .
$$

Since $\frac{\partial \pi_{i}}{\partial q_{i}}\left(q_{i}^{*}, q_{j}^{*}, H_{i}\right)=0$ by construction, $\frac{\partial \pi_{i}}{\partial q_{j}}=q_{i} P^{\prime}(Q)$ and $\frac{\partial \pi_{i}}{\partial H_{i}}=$ $\tilde{c}-F$, this yields:

$$
\left(\mathbb{E}\left[U^{\prime}\left(\pi_{i}\right)\right]\left(P^{\prime}\left(Q^{*}\right) q_{i}^{*} \frac{\partial q_{j}^{*}}{\partial H_{i}}-F\right)+\mathbb{E}\left[U^{\prime}\left(\pi_{i}\right) \tilde{c}\right]\right)\left(q_{i}^{*}, q_{j}^{*}, H_{i}^{*}\right)=0 .
$$

Dividing by $\mathbb{E}\left[U^{\prime}\left(\pi_{i}\right)\right]>0$ and selecting $H_{i}^{*}=H_{j}^{*}=H^{*}$ yields equation (7).

2. Equations (7), (6), and (5) yield:

$$
\frac{\partial q_{j}^{*}}{\partial H_{i}}\left(H^{*}, H^{*}\right)<0 \Leftrightarrow c\left(q^{*}, q^{*}, H\right)<F \Leftrightarrow H^{*}>q^{*}
$$


Thus, at the symmetric equilibrium:

$$
\begin{aligned}
& P\left(2 q^{*}\right)+q^{*} P^{\prime}\left(2 q^{*}\right)=c\left(q^{*}, q^{*}, H\right)<F=P\left(2 q^{E}(F, F)\right)+q^{E}(F, F) P^{\prime}\left(2 q^{E}(F, F)\right) \\
& \Leftrightarrow \\
& \qquad q^{*}>q^{E}(F, F) \\
& \text { since }\left(P(2 q)+q P^{\prime}(2 q)\right) \text { is decreasing by Condition 1. }
\end{aligned}
$$

A marginal increase in $H_{i}$ has two effects on firm's $i$ expected utility. First, a direct expected cost effect: the firm substitutes input at known cost $F$ for input at uncertain cost $\tilde{c}$. When taking the risk-ajusted expectation, this substitution is worth $\left(c_{i}\left(q_{i}, q_{j}, H_{i}\right)-F\right)$. Second, an indirect effect, through the change in the other firm's production: $\left(P^{\prime}\left(Q^{*}\right) q_{i}^{*} \frac{\partial q_{j}^{*}}{\partial H_{i}}\right)$. At the equilibrium, both effects exactly cancel out for both firms, which produces equilibrium conditions (7).

Thus, since $\frac{\partial q_{j}^{*}}{\partial H_{i}}\left(H^{*}, H^{*}\right)<0$ and $P^{\prime}\left(Q^{*}\right) q_{i}^{*}<0$, firms set $c_{i}\left(q_{i}^{*}, q_{j}^{*}, H_{i}^{*}\right)<$ $F$ : firms over hedge, i.e., hedge more than their (anticipated) production, so that their risk-adjusted expected marginal cost is lower than their "true" expected marginal cost $\mathbb{E}[\tilde{c}]=F$. This then leads them to become more aggressive, and produce more than if they were completed covered.

Finally, combining first-order conditions (6) and (7) yields:

$$
\left(P\left(Q^{*}\right)-F+q_{i}^{*} P^{\prime}\left(Q^{*}\right)\right)\left(H_{i}^{*}, H_{j}^{*}\right)=\left(-P^{\prime}\left(Q^{*}\right) q_{i}^{*} \frac{\partial q_{j}^{*}}{\partial H_{i}}\right)\left(H_{i}^{*}, H_{j}^{*}\right) .
$$

for $i=1,2$. Comparing with first-order condition (2) for $c_{i}=F$, an additional term $\left(-P^{\prime}\left(Q^{*}\right) q_{i}^{*} \frac{\partial q_{j}^{*}}{\partial H_{i}}\right)$ is added, that captures the strategic impact of firm $i$ 's hedging on firm $j$ 's production decision, in the sense of Fudenberg and Tirole (1984).

\section{Under-hedging to commit to higher price}

An argument similar to quantity competition shows that risk averse firms committing to their hedging position before making their pricing decision constitutes the only timing where strategic interactions arise. Since the analysis is similar to quantity competition, results are stated briefly, and differences with quantity competition are emphasized. 


\subsection{Demand and constant input costs}

Consider two symmetric firms that compete in price. Firm $i$ faces demand $D_{i}\left(p_{i}, p_{j}\right)$, decreasing in own price and increasing in the other firm's price, and constant input $\operatorname{cost} c_{i}$. With a slight abuse, we use the same notation as for quantity competition. Firm's $i$ profit is

$$
\pi_{i}^{R}\left(p_{i}, p_{j}, c_{i}\right)=D_{i}\left(p_{i}, p_{j}\right)\left(p_{i}-c_{i}\right) .
$$

Assumption $2 D_{i}\left(p_{i}, p_{j}\right)$ is such that, for $i=1,2:(i) \pi_{i}^{R}$ is concave in $p_{i}$ :

$$
\frac{\partial^{2} \pi_{i}^{R}}{\left(\partial p_{i}\right)^{2}}\left(p_{i}, p_{j}, c_{i}\right)<0 \text { for all }\left(p_{i}, p_{j}, c_{i}\right),
$$

(ii) for all $\left(c_{i}, c_{j}\right)$ "close enough" ${ }^{\prime \prime 3}$, the pricing game with constant costs $c_{i}$ and $c_{j}$ has a unique interior equilibrium $\left(p_{i}^{E}\left(c_{i}, c_{j}\right), p_{j}^{E}\left(c_{j}, c_{i}\right)\right)$ solution of

$$
\left(\left(p_{i}-c_{i}\right) \frac{\partial D_{i}}{\partial p_{i}}+D_{i}\right)\left(p_{i}^{E}\left(c_{i}, c_{j}\right), p_{j}^{E}\left(c_{j}, c_{i}\right)\right)=0
$$

(iii) prices are strategic complements:

$$
\frac{\partial^{2} \pi_{i}^{R}}{\partial p_{i} \partial p_{j}}\left(p_{i}^{E}\left(c_{i}, c_{j}\right), p_{j}^{E}\left(c_{j}, c_{i}\right)\right)>0 \text { for all }\left(c_{i}, c_{j}\right),
$$

and (iv) own price effect is stronger than other's price effect:

$$
\frac{\partial D_{i}}{\partial p_{i}}+\frac{\partial D_{i}}{\partial p_{j}}<0 \text { and } \frac{\partial^{2} D_{i}}{\left(\partial p_{i}\right)^{2}}+\frac{\partial^{2} D_{i}}{\partial p_{i} \partial p_{j}} \leq 0 \text { for all }\left(p_{i}, p_{j}\right) .
$$

Assumptions 2 is met for example for a linear Hotelling demand:

$$
D_{i}\left(p_{i}, p_{j}\right)=\frac{1}{2}+\frac{p_{j}-p_{i}}{2 t}
$$

in which case equilibrium prices are:

$$
p_{i}^{E}\left(c_{i}, c_{j}\right)=t+\frac{2 c_{i}+c_{j}}{2} .
$$

Concavity of the objective function and strategic complementarity of prices are met by many demand functions. Unicity of equilibrium with constant in-

\footnotetext{
${ }^{3}$ As in the Cournot case, $\left|c_{i}-c_{j}\right|$ must be small enough to avoid a corner equilibrium $D_{i}\left(p_{i}^{E}\left(c_{i}, c_{j}\right), p_{j}^{E}\left(c_{j}, c_{i}\right)\right)>0$ while $D_{j}\left(p_{j}^{E}\left(c_{j}, c_{i}\right), p_{i}^{E}\left(c_{i}, c_{j}\right)\right)=0$. Since we ultimately consider symmetric equilibria, we assume this condition holds.
} 
put costs is required to establish unicity with stochastic input costs. We prove in Appendix A that own price effect stronger than other's price effect is sufficient to guarantee that an increase in one firm's cost increases both prices:

$$
\frac{\partial p_{i}^{E}}{\partial c_{i}}\left(c_{i}, c_{j}\right)>0 \text { and } \frac{\partial p_{j}^{E}}{\partial c_{i}}\left(c_{j}, c_{i}\right)>0 .
$$

\subsection{Random input costs}

Firm $i$ 's profits for input price $\tilde{c}$ is:

$$
\begin{aligned}
\pi_{i}\left(p_{i}, p_{j}, H_{i} ; \tilde{c}\right) & =D\left(p_{i}, p_{j}\right)\left(p_{i}-\tilde{c}\right)+H_{i}(\tilde{c}-F) \\
& =D\left(p_{i}, p_{j}\right)\left(p_{i}-F\right)+\left(H_{i}-D\left(p_{i}, p_{j}\right)\right)(\tilde{c}-F) .
\end{aligned}
$$

The expected value for shareholders is

$$
v_{i}\left(p_{i}, p_{j}, H_{i}\right)=\mathbb{E}\left[U\left(\pi_{i}\left(p_{i}, p_{j}, H_{i} ; \tilde{c}\right)\right)\right] .
$$

Substituting in $\left(p_{i}^{*}\left(H_{i}, H_{j}\right), p_{j}^{*}\left(H_{i}, H_{j}\right)\right)$, the equilibrium of the pricing game for hedging volumes $\left(H_{i}, H_{j}\right)$, the expected value of firm $i$ is

$$
V_{i}\left(H_{i}, H_{j}\right)=v_{i}\left(p_{i}^{*}\left(H_{i}, H_{j}\right), p_{j}^{*}\left(H_{i}, H_{j}\right), H_{i}\right) .
$$

$$
\begin{aligned}
\frac{\partial v_{i}}{\partial p_{i}} & =\mathbb{E}\left[U^{\prime}\left(\pi_{i}\left(p_{i}, p_{j}, H_{i} ; \tilde{c}\right)\right) \frac{\partial \pi_{i}}{\partial p_{i}}\right] \\
& =\mathbb{E}\left[U^{\prime}\left(\pi_{i}\right) \cdot\left(D_{i}+\left(p_{i}-\tilde{c}\right) \frac{\partial D_{i}}{\partial p_{i}}\right)\right] \\
& =\mathbb{E}\left[U^{\prime}\left(\pi_{i}\right)\right]\left(D_{i}+p_{i} \frac{\partial D_{i}}{\partial p_{i}}-c_{i}\left(p_{i}, p_{j}, H_{i}\right)\right)
\end{aligned}
$$

where

$$
\begin{aligned}
& c_{i}\left(p_{i}, p_{j}, H_{i}\right)=\frac{\mathbb{E}\left[U^{\prime}\left(\pi_{i}\left(p_{i}, p_{j}, H_{i}\right)\right) \tilde{c}\right]}{\mathbb{E}\left[U^{\prime}\left(\pi_{i}\left(p_{i}, p_{j}, H_{i}\right)\right)\right]}=F+\frac{\operatorname{cov}\left[U^{\prime}\left(\pi_{i}\left(p_{i}, p_{j}, H_{i}\right)\right), \tilde{c}\right]}{\mathbb{E}\left[U^{\prime}\left(\pi_{i}\left(p_{i}, p_{j}, H_{i}\right)\right)\right]} . \\
& \frac{\partial^{2} v_{i}}{\partial p_{i}^{2}}=\mathbb{E}\left[U^{\prime \prime}\left(\pi_{i}\left(p_{i}, p_{j}, H_{i} ; \tilde{c}\right)\right)\left(\frac{\partial \pi_{i}}{\partial p_{i}}\right)^{2}+U^{\prime}\left(\pi_{i}\left(p_{i}, p_{j}, H_{i} ; \tilde{c}\right)\right) \frac{\partial^{2} \pi_{i}}{\partial p_{i}^{2}}\right]<0 .
\end{aligned}
$$

Since $v_{i}\left(p_{i}, p_{j}, H_{i}\right)$ is concave in $p_{i}$, if an interior Nash equilibrium of 
the pricing game $\left(p_{i}^{*}\left(H_{i}, H_{j}\right), p_{j}^{*}\left(H_{i}, H_{j}\right)\right)$ exists, it solves the system of the necessary first-order conditions:

$$
\left(p_{i}^{*}-c_{i}\left(p_{i}^{*}, p_{j}^{*}, H_{i}\right)\right) \frac{\partial D_{i}}{\partial p_{i}}\left(p_{i}^{*}, p_{j}^{*}\right)+D_{i}\left(p_{i}^{*}, p_{j}^{*}\right)=0
$$

for $i=1,2$.

As proven in Appendix B, the risk adjusted expected cost present similar properties to the Cournot case:

Lemma 2 For any $\left(H_{i}, H_{j}\right)$ :

$$
\frac{\partial c_{i}}{\partial p_{i}}\left(p_{i}^{*}, p_{j}^{*}, H_{i}\right)<0 \text { and } H_{i}<D_{i}\left(p_{i}^{*}, p_{j}^{*}\right) \Leftrightarrow c_{i}\left(p_{i}^{*}, p_{j}^{*}, H_{i}\right)>F .
$$

For any $\left(p_{i}, p_{j}, H_{i}\right)$ :

$$
\begin{gathered}
\frac{\partial c_{i}}{\partial H_{i}}\left(p_{i}, p_{j}, H_{i}\right)>0 . \\
\frac{\partial c_{i}}{\partial p_{j}}=\frac{\partial D_{i}}{\partial p_{j}}\left\{\left(p_{i}-c_{i}\right) \widehat{\mathbb{E}}\left[\rho\left(\pi_{i}\right)\left(c_{i}-\tilde{c}\right)\right]+\widehat{\mathbb{E}}\left[\rho\left(\pi_{i}\right)\left(c_{i}-\tilde{c}\right)^{2}\right]\right\} .
\end{gathered}
$$

The equilibrium of the two-stage game is then characterized as follows:

Proposition 3 1. For any $\left(H_{i}, H_{j}\right)$ "close enough", there exists an interior equilibrium of the pricing game characterized by equations (9) for $i=1,2$.

2. If absolute risk aversion is constant, this equilibrium is unique, and a marginal hedging increase by firm i reduces firm j's equilibrium price:

$$
\frac{\partial p_{j}^{*}}{\partial H_{i}}\left(H_{i}, H_{j}\right)<0
$$

3. If an interior equilibrium $\left(H_{i}^{*}, H_{j}^{*}\right)$ of the hedging game exists, it is characterized by

$$
\left(c_{i}\left(p_{i}^{*}, p_{j}^{*}, H_{i}\right)-F-\left(\frac{\frac{\partial D_{i}}{\partial p_{j}}\left(p_{i}^{*}, p_{j}^{*}\right)}{\frac{\partial D_{i}}{\partial p_{i}}\left(p_{i}^{*}, p_{j}^{*}\right)} D_{i}\left(p_{i}^{*}, p_{j}^{*}\right) \frac{\partial p_{j}^{*}}{\partial H_{i}}\right)\right)\left(H_{i}^{*}, H_{j}^{*}\right)=0
$$

for $i=1,2$.

4. If a symmetric interior equilibrium exists, and absolute risk aversion is constant, hedging softens price competition: firms under-hedge to com- 
mit to higher prices than if marginal costs were constant and equal to F:

$$
c_{i}\left(p^{*}, p^{*}, H^{*}\right)>F \Leftrightarrow H^{*}<D\left(p^{*}, p^{*}\right) \Leftrightarrow p^{*}>p^{E}(F, F) .
$$

Proof. The proof follows the steps of Propositions 1 and 2. Details are presented in Appendix B. The risk-adjusted costs are bounded, thus the sets in which we look for a fixed point is compact and convex in $\mathbb{R}^{2}$. Since all functions are continuous, Brouwer's fixed point theorem guarantees the existence of an equilibrium. If absolute risk aversion is constant, then Assumption 2 guarantees unicity of the equilibrium and the direction of the strategic effect. Equation (10) is derived similarly to equation (7). Comparison of equations (10), (8), and (9), proves that hedging softens price competition.

Combining the first-order conditions yields:

$$
\left(p^{*}-F\right) \frac{\partial D_{i}}{\partial p_{i}}\left(p^{*}, p^{*}\right)+D_{i}\left(p^{*}, p^{*}\right)=\left(\frac{\partial D_{i}}{\partial p_{j}}\left(p^{*}, p^{*}\right) D_{i}\left(p^{*}, p^{*}\right) \frac{\partial p_{j}^{*}}{\partial H_{i}}\right)\left(H^{*}, H^{*}\right) .
$$

Hedging creates a strategic effect, captured by the term $\frac{\partial p_{j}^{*}}{\partial H_{i}}$. Publicly keeping a portion of their input price exposure uncovered commits firms to raise prices to reduce demand, hence exposure. This commitment then yields a higher equilibrium price : $p^{*}>p^{E}(F, F)$.

The direction of the strategic effect is reversed compared to Cournot competition: here, firms under-hedge, hence increase the equilibrium price. This stark difference is best understood by comparing the first-order conditions:

$$
c_{i}-F+\frac{\partial \pi_{i}}{\partial q_{j}} \frac{\partial q_{j}^{*}}{\partial H_{i}}=0 \text { and } c_{i}-F+\frac{\partial \pi_{i}}{\partial p_{j}} \frac{\partial p_{j}^{*}}{\partial H_{i}}=0
$$

In both cases, when firm $i$ increases hedging, firm $j$ reduces her strategic variable (quantity or price). If firms compete in quantity, when firm $j$ increases output, he reduces firm's $i$ profit $\left(\frac{\partial \pi_{i}}{\partial q_{j}}<0\right)$, therefore, at the equilibrium, firm $i$ hedges to set her expected risk adjusted cost lower than $F$, i.e., becomes more aggressive. Conversely, if firms compete in price, when firm $j$ raises his price, he increases firm $i$ profit $\left(\frac{\partial \pi_{i}}{\partial p_{j}}>0\right)$, hence firm $i$ hedges to set her risk adjusted cost higher than $F$, i.e., becomes less aggressive.

\section{Robustness of the results}

Constant absolute risk aversion is the single sufficient condition for $(i)$ the second-stage equilibrium to be unique, and (ii) hedging to toughen quantity 
competition. This condition is extremely strong. We derive in Appendix C the necessary and sufficient conditions for these properties. All can be cast as an upper bound on

$$
\left|\frac{\partial c_{i}}{\partial q_{j}}\right|=q_{i}\left|P^{\prime}(Q) \widehat{\mathbb{E}}\left[\rho\left(\pi_{i}\right)\left(c_{i}-\tilde{c}\right)\right]\right|=q_{i}\left|P^{\prime}(Q) \operatorname{cov}\left[\rho\left(\pi_{i}\right), \tilde{c}\right]\right| .
$$

We observe that $\left|\widehat{\mathbb{E}}\left[\rho\left(\pi_{i}\right)\left(c_{i}-\tilde{c}\right)\right]\right|$ is bounded above:

$$
\left|\widehat{\mathbb{E}}\left[\rho\left(\pi_{i}\right)\left(c_{i}-\tilde{c}\right)\right]\right| \leq\left(\rho_{\max }-\rho_{\min }\right) \widehat{\mathbb{E}}\left[\max \left(c_{i}-\tilde{c}, 0\right)\right] \leq\left(\rho_{\max }-\rho_{\min }\right)(\bar{c}-\underline{c}) .
$$

Thus, $\mathcal{S}$ defined as

$$
\mathcal{S}=\left\{x: x \geq\left|\operatorname{cov}\left[\rho\left(\pi_{i}\right), \tilde{c}\right]\right|\left(q_{i}, q_{j}, H_{i}\right) \text { for all }\left(q_{i}, q_{j}, H_{i}\right) \in\left[0, \bar{q}^{E}\right]^{2} \times \mathbb{R}^{+}\right\}
$$

is not empty since $\left(\rho_{\max }-\rho_{\min }\right)(\bar{c}-\underline{c}) \in \mathcal{S} . R=\inf (\mathcal{S})$ exists, and

$$
\left|\frac{\partial c_{i}}{\partial q_{j}}\right| \leq \bar{q}^{E}\left|P^{\prime}(Q)\right| R \leq \bar{q}^{E}\left|P^{\prime}(Q)\right|\left(\rho_{\max }-\rho_{\min }\right)(\bar{c}-\underline{c}) .
$$

Proposition 4 If the covariance of input costs and the risk aversion of profits is lower than a threshold, that depends on the convexity of inverse demand $P($.$) , the equilibrium of the production game is unique and hedging toughens$ quantity competition. Specifically, the sufficient condition for unicity of the equilibrium and $\frac{\partial q_{j}^{*}}{\partial H_{i}}\left(H^{*}, H^{*}\right)<0$ is

$$
\left\{\begin{array}{c}
\bar{q}^{E} R \leq(\sqrt{3}-1) \text { if } P^{\prime \prime}(Q)>0 \\
\bar{q}^{E} R \leq(2 \sqrt{3}-3) \text { if } P^{\prime \prime}(Q)<0 \\
\bar{q}^{E} R \leq 1 \quad \text { if } P^{\prime \prime}(Q)=1
\end{array}\right.
$$

Proof. Details of the proof are presented in Appendix C. We derive sufficient conditions for each property, then we determine the highest upper bound such that all three sufficient conditions are satisfied.

If absolute risk aversion is constant, $\rho_{\max }=\rho_{\min }$, these sufficient conditions are met for any inverse demand function and any bounded distribution of input costs. If absolute risk aversion is not constant, which is more realistic, they provide an upper on the covariance between risk aversion of profit and input cost. 
A similar analysis can be conducted for price competition, although the algebra is more cumbersome. Define

$$
m=\min _{p \in\left[0, p^{E}(\bar{c}, \bar{c})\right]}\left(\frac{-\left(2 \frac{\partial D_{i}}{\partial p_{i}}+\frac{\partial D_{i}}{\partial p_{j}}+\frac{D_{i}}{\left(-\frac{\partial D_{i}}{\partial p_{i}}\right)}\left(\frac{\partial^{2} D_{i}}{\left(\partial p_{i}\right)^{2}}+\frac{\partial^{2} D_{i}}{\partial p_{i} \partial p_{j}}\right)\right)}{\frac{\partial D_{i}}{\partial p_{j}} D_{i}}\right)(p, p) .
$$

$m$ exists, since the function is continuous on a compact, and $m>0$ since $-\left(2 \frac{\partial D_{i}}{\partial p_{i}}+\frac{\partial D_{i}}{\partial p_{j}}+\frac{D_{i}}{\left(-\frac{\partial D_{i}}{\partial p_{i}}\right)}\left(\frac{\partial^{2} D_{i}}{\left(\partial p_{i}\right)^{2}}+\frac{\partial^{2} D_{i}}{\partial p_{i} \partial p_{j}}\right)\right)<0$. We prove in Appendix C that:

Proposition 5 If the covariance of risk aversion of profits with input cost is lower than $m$, hedging softens price competition:

$$
R \leq m \Rightarrow \frac{\partial p_{j}^{*}}{\partial H_{i}}\left(H^{*}, H^{*}\right)<0 .
$$

\section{Strategic incentive to commit to a hedging position}

Sofar, we have argued that firms commit to their hedging strategy under pressure from Boards of Directors not to speculate: risk managers are not allowed to significantly modify their derivatives position. This restriction has clear advantages in terms of monitoring the activity of traders. What is the strategic impact of this commitment?

First, if firms hedge after setting prices (or quantity), they completely eliminate their exposure to input cost. Conversely, when they hedge before they set prices (or quantities), they keep a portion of their exposure open. Their profits' volatility is increased, hence, ceteris paribus, their expected utility is decreased.

Second, if firms compete in quantity, commitment yields higher output, hence lower price. Thus we expect commitment yields a Pareto inferior outcome. On the other hand, if firms compete in price, commitment yields higher price, thus, if total demand is very inelastic (e.g., Hotelling competition), higher profits, which may compensate for the reduction in volatility.

In this Section, we refine this intuition. Consider a new game. The timing is now as follows: at $t=0$, firms either Commit $(C)$ or Not Commit $(N C)$ to their initial hedging strategy. At $t=1$, firms determine and publicly announce their initial hedging strategy. At $t=2$, they determine and publicly announce 
their output (or price). Finally, at $t=3$, if they have not committed at $t=0$, they can modify their initial hedging strategy. Then, input cost is realized, and profits are determined.

The expected utility to firm $i$ that plays strategy $X_{i} \in\{C, N C\}$ while firm $j$ plays strategy $X_{j} \in\{C, N C\}$ is $V_{i}\left(X_{i}, X_{j}\right)$

To focus on the strategic impact of hedging, we continue to assume that (i) there are no transaction costs associated with hedging, and (ii) the forward price $F$ as well as the expected spot price $\mathbb{E}[\tilde{c}]$ are equal and constant. Hedging before or after playing the product market game does not modify the (expected) gains.

We assume that the equilibrium of the second stage is unique (for example, constant risk aversion), and that a unique symmetric equilibrium of the hedging game exists.

Proposition 6 1. Not Committing cannot be sustained in equilibrium. Whether firms compete in quantity or in price,

$$
V(C, N C)>V(N C, N C)
$$

2. If firms compete in quantity, Not Committing is Pareto superior

$$
V(N C, N C)>V(C, C)
$$

3. If firms competing à la Hotelling have a constant absolute risk aversion and input costs are normally distributed, Committing is a Pareto superior to Non Committing

$$
V(C, C)>V(N C, N C)
$$

and is a dominant strategy

$$
V(C, C)>V(N C, C)
$$

Proof. We first prove point 1 if firms compete in quantity. Suppose firm 2 plays $N C$. If firm 1 plays $N C$, its expected utility is $V_{1}(N C, N C)$. Suppose now firm 1 plays $C$. At $t=3$, firm 2 optimally selects $\bar{H}_{2}=\bar{q}_{2}$. At $t=2$, both firms select output. Assuming a unique interior equilibrium $\left(\bar{q}_{1}\left(H_{1}\right), \bar{q}_{2}\left(H_{1}\right)\right)$ 
exists, it is characterized by:

$$
\left\{\begin{array}{c}
\bar{q}_{2} P^{\prime}\left(\bar{q}_{1}+\bar{q}_{2}\right)+P\left(\bar{q}_{1}+\bar{q}_{2}\right)-F=0 \\
\bar{q}_{1} P^{\prime}\left(\bar{q}_{1}+\bar{q}_{2}\right)+P\left(\bar{q}_{1}+\bar{q}_{2}\right)-c\left(\bar{q}_{1}, \bar{q}_{2}, H_{1}\right)=0
\end{array}\right.
$$

At $t=1$, firm 1 selects $\bar{H}_{1}$ to maximize $V_{1}\left(\bar{q}_{1}\left(H_{1}\right), \bar{q}_{2}\left(H_{1}\right), H_{1}\right)$. If firm 1 selects $H_{1}=q^{E}(F, F), q_{1}=q_{2}=q^{E}(F, F)$ is a solution of the system, hence is the unique equilibrium for $H_{1}=q^{E}(F, F)$. Thus, since there is no guarantee that $H_{1}=q^{E}(F, F)$ is optimal, we must have: $V_{1}(C, N C) \geq V_{1}(N C, N C)$. Then,

$$
\begin{aligned}
\frac{d V_{1}}{d H_{1}}\left(q^{E}(F, F)\right) & =\mathbb{E}\left[U^{\prime}\left(\pi_{1}\right)\left(\bar{q}_{1} P^{\prime}(\bar{Q}) \frac{d \bar{q}_{2}}{d H_{1}}+(\omega-F)\right)\right] \\
& =\bar{q}_{1} P^{\prime}(\bar{Q}) \frac{d \bar{q}_{2}}{d H_{1}} \mathbb{E}\left[U^{\prime}\left(\pi_{1}\right)\right]
\end{aligned}
$$

since $c_{1}\left(q^{E}(F, F)\right)=F$. Then, since $H_{1}=\bar{q}_{1}$, $\frac{\partial c_{1}}{\partial q_{2}}=0$, hence $\frac{d \bar{q}_{2}}{d H_{1}}<0$. Thus, $\frac{d V_{1}}{d H_{1}}\left(q^{E}(F, F)\right)>0$, hence for $\varepsilon>0$ arbitrarily small, $V_{1}\left(q^{E}(F, F+\varepsilon)\right)>$ $V_{1}\left(q^{E}(F, F)\right) \geq V(N C, N C)$. Thus:

$$
V(C, N C)>V(N C, N C)
$$

The proof of point 1 proceeds along the same lines if firms compete in price, and is presented in Appendix D, along with formal proof of the other points. As expected, when firms compete in quantity, $(C, C)$ yields lower price and higher volatility, hence is Pareto inferior to $(N C, N C)$. On the other hand, if firms compete à la Hotelling, the expected retail profit increase compensates for the loss from increased volatility, hence (i) Committing is Pareto superior: $V(C, C)>V(N C, N C)$, and $(i i)$ is the best response to the other firm's Committing: $V(C, C)>V(N C, C)$.

The first point is striking: even though both firms Non Committing is Pareto superior for firms competing in quantity, an individual firm prefers to Commit when the other one does not, since she can always do strictly better than replicating the Non Committing outcome.

Thus, whether firms compete in quantity or in price, they have a strategic incentive to commit, as well as a risk control objective. 


\section{Concluding remarks}

This article examines how firms facing volatile input prices and holding some degree of market power in their product market link their risk management and production or pricing strategies. This issue is relevant in many industries ranging from manufacturing to energy retailing, where risk averse firms decide on their hedging strategies before their product market strategies. We find that hedging modifies the pricing and production strategies of firms. This strategic effect is channelled through the expected risk-adjusted cost, i.e., the expected marginal cost under the measure induced by investors' risk aversion, and has diametrically opposed impacts depending on the nature of product market competition: hedging toughens quantity competition while it softens price competition. Finally, committing to a hedging strategy is always a best response to non committing, and is a dominant strategy if firms compete à la Hotelling.

This work can be expanded in many directions. First, it would be interesting to endogenize pricing flexibility. We have assumed that industry practices dictate whether prices are flexible or not. This is true in practice. However, we would like to know under what conditions price flexibility is indeed an equilibrium.

Second, it would be interesting to examine asymmetric situations, such as when one firm is market leader and announces its hedging strategy before the other, or when different firms have different costs.

Finally, it would be interesting to test empirically these models' predictions, in particular whether firms incorporate their and their competitors' hedging in their pricing strategies. The airlines industry appears to offer fertile ground for analysis: airlines face volatile fuel cost, and appear to have retained some pricing power, at least on some routes. Furthermore, as evidenced by the rich academic literature (e.g., Carter, Rogers, and Simkins (2006) and (Gerardi and Shapiro (2009)) data on prices and hedging strategies are publicly available.

\section{References}

[1] T. Adam, S. Dasgupta, and S.Titma. Financial constraints, competition and hedging in industry equilibrium. The Journal of Finance, 62(5):2445-2473, October 2007.

[2] R. Aid, G. Chemla, A. Porchet, and N. Touzi. Hedging and vertical integration in energy markets. Management Science, 57(8):1438-1452, 
August 2011.

[3] B. Allaz and J-L. Vila. Cournot competition, futures markets and efficiency. Journal of Economic Theory, 59:1-16, 1993.

[4] H. Bessembinder and M. L. Lemmon. Equilibrium pricing and optimal hedging in electricity forward markets. The journal of finance, LVII(3):1347-1382, 2002.

[5] B. Biais, T. Mariotti, J.-C. Rochet, and S. Villeneuve. Dynamic security design: Convergence to continuous time and asset pricing implications. Review of Economics Studies, 74:345-390, 2007.

[6] G. Bodnar, B. Dumas, and R. Marston. Pass-through and exposure. The Journal of Finance, 57(1):199-231, February 2002.

[7] P. Bolton, H. Chen, and N. Wang. A unified theory of tobin's q, corporate investment, financing, and risk management. The Journal of Finance, 66:1545-1578, 2011.

[8] D. Carter, D. Rogers, and B. Simkins. Does hedging affect firm value? evidence from the u.s. airline industry. Financial Management, 35:53-86, 2006.

[9] Peter DeMarzo and Y. Sannikov. Optimal security design and dynamic capital structure in a continuous time agency model. Journal of Finance, 61(6):2681-2724, December 2006.

[10] J.-P. Descamps, T. Mariotti, J.-C. Rochet, and S. Villeneuve. Free cash flows, issuance costs, and stock prices. Journal of Finance, 66(5):15011544, October 2011.

[11] K. Froot, D. Sharfstein, and J. Stein. Risk management: Coordinating corporate investment and financing policies. Journal of Finance, 48:1629-1658, 1993.

[12] K. A. Froot and J. C. Stein. Risk management, capital budgeting, and capital structure policy for financial institutions: An integrated approach. Journal of Financial Economics, 47:55-82, 1998.

[13] D. Fudenberg and J. Tirole. The fat cat effect, the puppy dog ploy and the lean and hungry look. American Economic Review, Papers and Proceedings, 74:361-368, 1984.

[14] K. S. Gerardi and A. H. Shapiro. Does competition reduce price dispersion? new evidence from the airline industry. Journal of Political Economy, 117(1):1-37, 2009.

[15] Y. Jin and P. Jorion. Firm value and hedging: Evidence from u.s. oil and gas producers. The Journal of Finance, 61:893-919, 2006. 
[16] F. Loss. Optimal hedging strategies and interactions between firms. Journal of Economics and Management Strategy, 21(1):79-129, 2012.

[17] Ofgem. Energy supply probe - initial findings report, October 2008. ref: $140 / 08$.

[18] J.-C. Rochet and S. Villeneuve. Liquidity risk and corporate demand for hedging and insurance. Journal of Financial Intermediation, 3:300-323, 2011.

[19] I. Sheldon and R. Sperling. Estimating the extent of imperfect competition in the food industry: What have we learned? Journal of Agricultural Economics, 54(1):89-109, 2003. 


\section{A Quantity competition}

$$
\begin{aligned}
\pi_{i}\left(q_{i}, q_{j}, H_{i} ; \tilde{c}\right) & =q_{i}(P(Q)-\tilde{c})+H_{i}(\tilde{c}-F) \\
& =q_{i}(P(Q)-F)+\left(H_{i}-q_{i}\right)(\tilde{c}-F) .
\end{aligned}
$$

Hence,

$$
\frac{\partial \pi_{i}}{\partial q_{i}}=P(Q)-\tilde{c}+q_{i} P^{\prime}(Q) \text { and } \frac{\partial \pi_{i}}{\partial q_{j}}=q_{i} P^{\prime}(Q)
$$

Define

$$
\psi\left(q_{i}, q_{j}, H_{i}\right)=P(Q)-c_{i}\left(q_{i}, q_{j}, H_{i}\right)+q_{i} P^{\prime}(Q) .
$$

The necessary conditions characterizing the equilibrium $\left(q_{i}^{*}\left(H_{i}, H_{j}\right), q_{j}^{*}\left(H_{i}, H_{j}\right)\right)$ of the production game are

$$
\psi\left(q_{i}^{*}, q_{j}^{*}, H_{i}\right)=\psi\left(q_{j}^{*}, q_{i}^{*}, H_{j}\right)=0 .
$$

Assuming an equilibrium exists and is given by the first-order conditions, total differentiation of the system of two equations with respect to $H_{i}$ yields:

$$
\left\{\begin{array}{c}
\left(\psi_{1} \frac{\partial q_{i}^{*}}{\partial H_{i}}+\psi_{2} \frac{\partial q_{j}^{*}}{\partial H_{i}}+\psi_{3}\right)\left(q_{i}^{*}, q_{j}^{*}, H_{i}\right)=0 \\
\left(\psi_{1} \frac{\partial q_{j}^{*}}{\partial H_{i}}+\psi_{2} \frac{\partial q_{i}^{*}}{\partial H_{i}}\right)\left(q_{j}^{*}, q_{i}^{*}, H_{j}\right)=0
\end{array},\right.
$$

where

$$
\left\{\begin{array}{c}
\psi_{1}\left(q_{i}, q_{j}, H_{i}\right)=2 P^{\prime}\left(q_{i}+q_{j}\right)+q_{i} P^{\prime \prime}\left(q_{i}+q_{j}\right)-\frac{\partial c_{i}}{\partial q_{i}} \\
\psi_{2}\left(q_{i}, q_{j}, H_{i}\right)=P^{\prime}\left(q_{i}+q_{j}\right)+q_{i} P^{\prime \prime}\left(q_{i}+q_{j}\right)-\frac{\partial c_{i}}{\partial q_{j}} \\
\psi_{3}\left(q_{i}, q_{j}, H_{i}\right)=-\frac{\partial c_{i}}{\partial H_{i}}
\end{array}\right.
$$

Thus, assuming $\Delta=\psi_{1}\left(q_{i}^{*}, q_{j}^{*}, H_{i}\right) \psi_{1}\left(q_{j}^{*}, q_{i}^{*}, H_{j}\right)-\psi_{2}\left(q_{i}^{*}, q_{j}^{*}, H_{i}\right) \psi_{2}\left(q_{j}^{*}, q_{i}^{*}, H_{j}\right) \neq$ 0 ,

$$
\left\{\begin{array}{l}
\frac{\partial q_{i}^{*}}{\partial H_{i}}\left(H_{i} H_{j}\right)=-\frac{\psi_{1}\left(q_{j}^{*}, q_{i}^{*}, H_{j}\right)}{\Delta} \psi_{3}\left(q_{i}^{*}, q_{j}^{*}, H_{i}\right) \\
\frac{\partial q_{j}^{*}}{\partial H_{i}}\left(H_{j}, H_{i}\right)=\frac{\psi_{2}\left(q_{j}^{*}, q_{i}^{*}, H_{j}\right)}{\Delta} \psi_{3}\left(q_{i}^{*}, q_{j}^{*}, H_{i}\right)
\end{array} .\right.
$$

\section{A.1 Impact of $c_{i}$ on $q_{i}^{E}$ and $q_{j}^{E}$ (constant input costs)}

Suppose first the marginal costs are constant, i.e., $c_{i}\left(q_{i}, q_{j}, H_{i}\right)=c_{i}$.

$$
\left\{\begin{array}{c}
\psi_{1}^{E}\left(q_{i}, q_{j}, c_{i}\right)=2 P^{\prime}\left(q_{i}+q_{j}\right)+q_{i} P^{\prime \prime}\left(q_{i}+q_{j}\right)<0 \\
\psi_{2}^{E}\left(q_{i}, q_{j}, c_{i}\right)=P^{\prime}\left(q_{i}+q_{j}\right)+q_{i} P^{\prime \prime}\left(q_{i}+q_{j}\right)<0 \\
\psi_{3}^{E}\left(q_{i}, q_{j}, c_{i}\right)=-1<0
\end{array} .\right.
$$


Then:

$$
\Delta=P^{\prime}\left(Q^{E}\right)\left(3 P^{\prime}\left(Q^{E}\right)+Q^{E} P^{\prime \prime}\left(Q^{E}\right)\right)>0,
$$

and

$$
\left\{\begin{array}{c}
\frac{\partial q_{i}^{E}}{\partial c_{i}}\left(c_{i}, c_{j}\right)=\frac{2 P^{\prime}\left(Q^{E}\right)+q_{j}^{E} P^{\prime \prime}\left(Q^{E}\right)}{P^{\prime}\left(Q^{E}\right)\left(3 P^{\prime}\left(Q^{E}\right)+Q^{E} P^{\prime \prime}\left(Q^{E}\right)\right)}<0 \\
\frac{\partial q_{j}^{E}}{\partial c_{i}}\left(c_{j}, c_{i}\right)=-\frac{P^{\prime}\left(Q^{E}\right)+q_{j}^{E} P^{\prime \prime}\left(Q^{E}\right)}{P^{\prime}\left(Q^{E}\right)\left(3 P^{\prime}\left(Q^{E}\right)+Q^{E} P^{\prime \prime}\left(Q^{E}\right)\right)}>0
\end{array} .\right.
$$

\section{A.2 Properties of the expected risk-adjusted cost (Lemma 1)}

For any $\left(q_{i}, q_{j}, H_{i}\right)$,

$$
\begin{aligned}
\frac{\partial c_{i}}{\partial q_{i}} & =\frac{\mathbb{E}\left[U^{\prime}\left(\pi_{i}\right)\right] \mathbb{E}\left[U^{\prime \prime}\left(\pi_{i}\right) \frac{\partial \pi_{i}}{\partial q_{i}} \tilde{c}\right]-\mathbb{E}\left[U^{\prime}\left(\pi_{i}\right) \tilde{c}\right] \mathbb{E}\left[U^{\prime \prime}\left(\pi_{i}\right) \frac{\partial \pi_{i}}{\partial q_{i}}\right]}{\left(\mathbb{E}\left[U^{\prime}\left(\pi_{i}\right)\right]\right)^{2}} \\
& =c_{i} \widehat{\mathbb{E}}\left[\rho\left(\pi_{i}\right) \frac{\partial \pi_{i}}{\partial q_{i}}\right]-\widehat{\mathbb{E}}\left[\rho\left(\pi_{i}\right) \frac{\partial \pi_{i}}{\partial q_{i}} \tilde{c}\right]=\widehat{\mathbb{E}}\left[\rho\left(\pi_{i}\right) \frac{\partial \pi_{i}}{\partial q_{i}}\left(c_{i}-\tilde{c}\right)\right] .
\end{aligned}
$$

For any $\left(H_{i}, H_{j}\right)$,

$$
\frac{\partial \pi_{i}}{\partial q_{i}}\left(q_{i}^{*}, q_{j}^{*}, H_{i}\right)=P\left(q_{i}^{*}+q_{j}^{*}\right)+q_{i}^{*} P^{\prime}\left(q_{i}^{*}+q_{j}^{*}\right)-\tilde{c}=c_{i}\left(q_{i}^{*}, q_{j}^{*}, H_{i}\right)-\tilde{c} .
$$

Thus:

$$
\frac{\partial c_{i}}{\partial q_{i}}\left(q_{i}^{*}, q_{j}^{*}, H_{i}\right)=\widehat{\mathbb{E}}\left[\rho\left(\pi_{i}\right)\left(c_{i}-\tilde{c}\right)^{2}\right]\left(q_{i}^{*}, q_{j}^{*}, H_{i}\right)>0 .
$$

For any $\left(q_{i}, q_{j}, H_{i}\right)$,

$$
\begin{aligned}
\frac{\partial c_{i}}{\partial H_{i}} & =\widehat{\mathbb{E}}\left[\rho\left(\pi_{i}\right) \frac{\partial \pi_{i}}{\partial H_{i}}\left(c_{i}-\tilde{c}\right)\right]=\widehat{\mathbb{E}}\left[\rho\left(\pi_{i}\right)(\tilde{c}-F)\left(c_{i}-\tilde{c}\right)\right] \\
& =-\widehat{\mathbb{E}}\left[\rho\left(\pi_{i}\right)\left(\tilde{c}-c_{i}\right)^{2}\right]+\left(c_{i}-F\right) \widehat{\mathbb{E}}\left[\rho\left(\pi_{i}\right)\left(c_{i}-\tilde{c}\right)\right] \\
& =-\left(\widehat{\mathbb{E}}\left[\rho\left(\pi_{i}\right)\left(\tilde{c}-c_{i}\right)^{2}\right]+\frac{\operatorname{cov}\left[U^{\prime}\left(\pi_{i}\right), \tilde{c}\right] \cdot \widehat{\operatorname{cov}}\left[\rho\left(\pi_{i}\right), \tilde{c}\right]}{\left(\mathbb{E}\left[U^{\prime}\left(\pi_{i}\right)\right]\right)}\right)
\end{aligned}
$$

since

$$
\widehat{\mathbb{E}}\left[\rho\left(\pi_{i}\right)\left(c_{i}-\tilde{c}\right)\right]=\widehat{\mathbb{E}}\left[\rho\left(\pi_{i}\right)(\widehat{\mathbb{E}}[\tilde{c}]-\tilde{c})\right]=-\widehat{\operatorname{cov}}\left[\rho\left(\pi_{i}\right), \tilde{c}\right] .
$$

Since $\rho($.$) and U^{\prime}($.$) are both non-increasing, \operatorname{cov}\left[U^{\prime}\left(\pi_{i}\right), \tilde{c}\right] \cdot \widehat{\operatorname{cov}}\left[\rho\left(\pi_{i}\right), \tilde{c}\right]>0$, hence $\frac{\partial c_{i}}{\partial H_{i}}<0$. 
Finally, for any $\left(q_{i}, q_{j}, H_{i}\right)$,

$$
\begin{aligned}
\frac{\partial c_{i}}{\partial q_{j}} & =\widehat{\mathbb{E}}\left[\rho\left(\pi_{i}\right) \frac{\partial \pi_{i}}{\partial q_{j}}\left(c_{i}-\tilde{c}\right)\right] \\
& =q_{i} P^{\prime}(Q) \widehat{\mathbb{E}}\left[\rho\left(\pi_{i}\right)\left(c_{i}-\tilde{c}\right)\right] \\
& =-q_{i} P^{\prime}(Q) \widehat{\operatorname{cov}}\left[\rho\left(\pi_{i}\right), \tilde{c}\right] .
\end{aligned}
$$

\section{A.3 Existence and unicity of equilibrium (Proposition 1)}

For existence, we apply Brouwer's fixed point theorem to the function $\Phi$, defined from $\mathbb{R}^{2}$ into $\mathbb{R}^{2}$ by

$$
\left\{\begin{array}{l}
\Phi_{1}\left(q_{1}, q_{2}\right)=q^{E}\left(c_{1}\left(q_{1}, q_{2}, H_{1}\right), c_{2}\left(q_{2}, q_{1}, H_{2}\right)\right) \\
\Phi_{2}\left(q_{1}, q_{2}\right)=q^{E}\left(c_{1}\left(q_{1}, q_{2}, H_{1}\right), c_{2}\left(q_{2}, q_{1}, H_{2}\right)\right)
\end{array} .\right.
$$

Since $q^{E}(x, y)$ and $c(x, y, z)$ are continuous in all their arguments, we need only to establish that $\left(q_{i}, q_{j}\right)$ lies in a compact and convex set of $\mathbb{R}^{2}$. Since $\widetilde{c} \leq \bar{c}$

$$
c_{i}\left(q_{i}, q_{j}, H_{i}\right)=\frac{\mathbb{E}\left[U^{\prime}\left(\pi_{i}\left(q_{i}, q_{j}, H_{i}\right)\right) \tilde{c}\right]}{\mathbb{E}\left[U^{\prime}\left(\pi_{i}\left(q_{i}, q_{j}, H_{i}\right)\right)\right]} \leq \bar{c}
$$

for all $\left(q_{i}, q_{j}, H_{i}\right)$. Thus, since $q_{i}^{E}$ is increasing in $c_{j}$ and decreasing in $c_{i}$ :

$$
q_{i}^{E}\left(c_{i}\left(q_{i}, q_{j}, H_{i}\right), c_{j}\left(q_{i}, q_{j}, H_{j}\right)\right) \leq q_{i}^{E}(0, \bar{c})=\bar{q}^{E}
$$

Since $q_{i} \geq 0$ by definition,we can limit our search for a fixed point to the compact and convex set $\left[0, \bar{q}^{E}\right]^{2}$. Brouwer's theorem then applies, and there exists a fixed point, i.e., an equilibrium. This equilibrium $\left(q_{1}^{*}, q_{2}^{*}\right)$ is unique if the real parts of the eigenvalues of the Jacobian $J\left(q_{1}^{*}, q_{2}^{*}, H_{1}, H_{2}\right)$ are negative, where

$$
J\left(q_{1}^{*}, q_{2}^{*}, H_{1}, H_{2}\right)=\left[\begin{array}{cc}
\frac{\partial q_{1}^{E}}{\partial q_{1}}-1 & \frac{\partial q_{1}^{E}}{\partial q_{2}} \\
\frac{\partial q_{2}^{E}}{\partial c_{1}} & \frac{\partial q_{2}^{E}}{\partial q_{2}}-1
\end{array}\right] .
$$

The eigenvalues are the roots of:

$$
\lambda^{2}-\lambda T r+D e t=0
$$

where $\operatorname{Tr}$ is the trace of $J\left(q_{1}^{*}, q_{2}^{*}, H_{1}, H_{2}\right)$ and Det its determinant. The roots are:

$$
\lambda_{ \pm}=\frac{\operatorname{Tr} \pm \sqrt{\operatorname{Tr}{ }^{2}-4 D e t}}{2} .
$$


If $T r^{2}-4 D e t<0$, the two roots are complex and conjugate. Their real part is negative if and only if $T r<0$. If $T r^{2}-4 D e t \geq 0$, the two roots are real. $\operatorname{Tr}+\sqrt{T r^{2}-4 D e t}<0$ requires $\operatorname{Tr}<0$. Then, it also requires Det $>0$. Thus, we require $\operatorname{Tr}<0$ and Det $>0$.

$$
\begin{aligned}
\operatorname{Tr}\left(q_{1}^{*}, q_{2}^{*}, H_{1}, H_{2}\right) & =\left(\frac{\partial q_{i}^{E}}{\partial q_{i}}+\frac{\partial q_{j}^{E}}{\partial q_{j}}-2\right)\left(q_{1}^{*}, q_{2}^{*}, H_{1}, H_{2}\right) \\
& =\left(\begin{array}{c}
\frac{\partial q_{i}^{E}}{\partial c_{i}} \frac{\partial c_{i}}{\partial q_{i}}+\underset{+}{-}+\frac{\partial q_{j}^{E}}{\partial c_{j}} \frac{\partial c_{j}}{\partial q_{j}}+\underset{+}{+}+\frac{\partial q_{i}^{E}}{\partial c_{j}} \frac{\partial c_{j}}{\partial q_{i}}+\underset{+}{\frac{\partial q_{j}}{\partial c_{i}}} \frac{\partial c_{i}}{\partial q_{j}}
\end{array}\right)\left(q_{1}^{*}, q_{2}^{*}, H_{1}, H_{2}\right)-2 .
\end{aligned}
$$

From Lemma 1,

$$
\rho \text { constant } \Rightarrow \frac{\partial c_{j}}{\partial q_{i}}=\frac{\partial c_{i}}{\partial q_{j}}=0 \Rightarrow \operatorname{Tr}\left(q_{1}^{*}, q_{2}^{*}, H_{1}, H_{2}\right)<-2<0 .
$$

We now examine $\operatorname{Det}\left(q_{1}^{*}, q_{2}^{*}, H_{1}, H_{2}\right)$.

$$
\begin{aligned}
\operatorname{Det}\left(q_{1}^{*}, q_{2}^{*}, H_{1}, H_{2}\right)= & \left(\left(\frac{\partial q_{i}^{E}}{\partial q_{i}}-1\right)\left(\frac{\partial q_{j}^{E}}{\partial q_{j}}-1\right)-\frac{\partial q_{i}^{E}}{\partial q_{j}} \frac{\partial q_{j}^{E}}{\partial q_{i}}\right)\left(q_{1}^{*}, q_{2}^{*}, H_{1}, H_{2}\right) \\
= & \left(\begin{array}{c}
\left(\frac{\partial q_{i}^{E}}{\partial c_{i}} \frac{\partial q_{j}^{E}}{\partial c_{j}}-\frac{\partial q_{i}^{E}}{\partial c_{j}} \frac{\partial q_{j}^{E}}{\partial c_{i}}\right)\left(\frac{\partial c_{i}}{\partial q_{i}} \frac{\partial c_{j}}{\partial q_{j}}-\frac{\partial c_{i}}{\partial q_{j}} \frac{\partial c_{j}}{\partial q_{i}}\right) \\
-\frac{\partial q_{i}^{E}}{\partial q_{i}}-\frac{\partial q_{j}^{E}}{\partial q_{j}}+1
\end{array}\right)\left(q_{1}^{*}, q_{2}^{*}, H_{1}, H_{2}\right) \\
= & \left(\frac{1}{P^{\prime}\left(Q^{*}\right)\left(3 P^{\prime}\left(Q^{*}\right)+Q^{*} P^{\prime \prime}\left(Q^{*}\right)\right)}\left(\frac{\partial c_{i}}{\partial q_{i}} \frac{\partial c_{j}}{\partial q_{j}}-\frac{\partial c_{i}}{\partial q_{j}} \frac{\partial c_{j}}{\partial q_{i}}\right)\right)\left(q_{1}^{*}, q_{2}^{*}, H_{1}, H_{2}\right) \\
& -\operatorname{Tr}\left(q_{1}^{*}, q_{2}^{*}, H_{1}, H_{2}\right)-1
\end{aligned}
$$

Thus,

$$
\rho \text { constant } \Rightarrow \frac{\partial c_{j}}{\partial q_{i}}=\frac{\partial c_{i}}{\partial q_{j}}=0 \Rightarrow \operatorname{Det}\left(q_{1}^{*}, q_{2}^{*}, H_{1}, H_{2}\right)>0 .
$$

\section{A.4 Impact of $H_{i}$ on $q_{j}^{*}$ with constant absolute risk aversion (Proposition 1)}

If $\rho$ is constant,

$$
\psi_{2}\left(q_{i}, q_{j}, H_{i}\right)=P^{\prime}\left(q_{i}+q_{j}\right)+q_{i} P^{\prime \prime}\left(q_{i}+q_{j}\right)<0
$$


and

$$
\psi_{3}\left(q_{i}, q_{j}, H_{i}\right)=-\frac{\partial c_{i}}{\partial H_{i}}\left(q_{i}, q_{j}, H_{i}\right)>0
$$

Then:

$$
\begin{aligned}
\Delta= & \left(2 P^{\prime}\left(Q^{*}\right)+q_{i}^{*} P^{\prime \prime}\left(Q^{*}\right)-\frac{\partial c_{i}}{\partial q_{i}}\right)\left(2 P^{\prime}\left(Q^{*}\right)+q_{j}^{*} P^{\prime \prime}\left(Q^{*}\right)-\frac{\partial c_{j}}{\partial q_{j}}\right) \\
& -\left(P^{\prime}\left(Q^{*}\right)+q_{i} P^{\prime \prime}\left(Q^{*}\right)\right)\left(P^{\prime}\left(Q^{*}\right)+q_{j} P^{\prime \prime}\left(Q^{*}\right)\right) \\
= & \left(P^{\prime}\left(Q^{*}\right)-\frac{\partial c_{i}}{\partial q_{i}}\right)\left(P^{\prime}\left(Q^{*}\right)-\frac{\partial c_{j}}{\partial q_{j}}\right)+\left(P^{\prime}\left(Q^{*}\right)-\frac{\partial c_{i}}{\partial q_{i}}\right)\left(P^{\prime}\left(Q^{*}\right)+q_{j}^{*} P^{\prime \prime}\left(Q^{*}\right)\right) \\
& +\left(P^{\prime}\left(Q^{*}\right)-\frac{\partial c_{j}}{\partial q_{j}}\right)\left(P^{\prime}\left(Q^{*}\right)+q_{i}^{*} P^{\prime \prime}\left(Q^{*}\right)\right) \\
> & 0 .
\end{aligned}
$$

Thus:

$$
\frac{\partial q_{j}^{*}}{\partial H_{i}}\left(q_{i}^{*}, q_{j}^{*}, H_{i}\right)=\frac{\psi_{2}\left(q_{j}^{*}, q_{i}^{*}, H_{i}\right)}{\Delta} \psi_{3}\left(q_{i}^{*}, q_{j}^{*}, H_{i}\right)<0 .
$$

\section{B Price competition}

Firm's $i$ profit is:

$$
\begin{aligned}
\pi_{i}\left(p_{i}, p_{j}, H_{i} ; \tilde{c}\right) & =D_{i}\left(p_{i}, p_{j}\right)\left(p_{i}-\tilde{c}\right)+H_{i}(\tilde{c}-F) \\
& =D_{i}\left(p_{i}, p_{j}\right)\left(p_{i}-F\right)+\left(H_{i}-D_{i}\left(p_{i}, p_{j}\right)\right)(\tilde{c}-F),
\end{aligned}
$$

hence:

$\frac{\partial \pi_{i}}{\partial p_{i}}\left(p_{i}, p_{j}\right)=\frac{\partial D_{i}}{\partial p_{i}}\left(p_{i}, p_{j}\right)\left(p_{i}-\tilde{c}\right)+D_{i}\left(p_{i}, p_{j}\right)$ and $\frac{\partial \pi_{i}}{\partial p_{j}}\left(p_{i}, p_{j}\right)=\frac{\partial D_{i}}{\partial p_{j}}\left(p_{i}, p_{j}\right)\left(p_{i}-\tilde{c}\right)$.

Define

$$
\psi\left(p_{i}, p_{j}, H_{i}\right)=\frac{\partial D_{i}}{\partial p_{i}}\left(p_{i}, p_{j}\right)\left(p_{i}-c_{i}\left(p_{i}, p_{j}, H_{i}\right)\right)+D_{i}\left(p_{i}, p_{j}\right) .
$$

The necessary first-order conditions characterizing an interior equilibrium $\left(p_{i}^{*}\left(H_{i}, H_{j}\right), p_{j}^{*}\left(H_{j}, H_{i}\right)\right)$ of the pricing game are

$$
\psi\left(p_{i}^{*}, p_{j}^{*}, H_{i}\right)=\psi\left(p_{j}^{*}, p_{i}^{*}, H_{j}\right)=0 .
$$


Assuming an interior equilibrium exists and $\Delta=\psi_{1}\left(p_{i}^{*}, p_{j}^{*}, H_{i}\right) \psi_{1}\left(p_{j}^{*}, p_{i}^{*}, H_{j}\right)-$ $\psi_{2}\left(p_{i}^{*}, p_{j}^{*}, H_{i}\right) \psi_{2}\left(p_{j}^{*}, p_{i}^{*}, H_{j}\right) \neq 0$,

$$
\left\{\begin{array}{c}
\frac{\partial p_{i}^{*}}{\partial H_{i}}\left(p_{i}^{*}, p_{j}^{*}, H_{i}\right)=-\frac{\psi_{1}\left(p_{j}^{*}, p_{i}^{*}, H_{j}\right)}{\Delta} \psi_{3}\left(p_{i}^{*}, p_{j}^{*}, H_{i}\right) \\
\frac{\partial p_{j}^{*}}{\partial H_{i}}\left(p_{i}^{*}, p_{j}^{*}, H_{i}\right)=\frac{\psi_{2}\left(p_{j}^{*}, p_{i}^{*}, H_{j}\right)}{\Delta} \psi_{3}\left(p_{i}^{*}, p_{j}^{*}, H_{i}\right)
\end{array} .\right.
$$

where

$$
\left\{\begin{array}{c}
\psi_{1}\left(p_{i}, p_{j}, H_{i}\right)=2 \frac{\partial D_{i}}{\partial p_{i}}+\left(p_{i}-c_{i}\right) \frac{\partial^{2} D_{i}}{\left(\partial p_{i}\right)^{2}}-\frac{\partial D_{i}}{\partial p_{i}} \frac{\partial c_{i}}{\partial p_{i}} \\
\psi_{2}\left(p_{i}, p_{j}, H_{i}\right)=\frac{\partial D_{i}}{\partial p_{j}}+\left(p_{i}-c_{i}\right) \frac{\partial^{2} D_{i}}{\partial p_{i} \partial p_{j}}-\frac{\partial D_{i}}{\partial p_{i}} \frac{\partial c_{i}}{\partial p_{j}} \\
\psi_{3}\left(p_{i}, p_{j}, H_{i}\right)=-\frac{\partial D_{i}}{\partial p_{i}} \frac{\partial c_{i}}{\partial H_{i}} .
\end{array}\right.
$$

\section{B.1 Impact of $c_{i}$ on $p_{i}^{E}$ and $p_{j}^{E}$ (constant input costs)}

Suppose first the marginal costs are constant:

$$
\psi^{E}\left(p_{i}, p_{j}, c_{i}\right)=\frac{\partial D_{i}\left(p_{i}, p_{j}\right)}{\partial p_{i}}\left(p_{i}-c_{i}\right)+D_{i}\left(p_{i}, p_{j}\right)
$$

and

$$
\left\{\begin{array}{c}
\psi_{1}^{E}\left(p_{i}, p_{j}, c_{i}\right)=2 \frac{\partial D_{i}}{\partial p_{i}}+\left(p_{i}-c_{i}\right) \frac{\partial^{2} D_{i}}{\left(\partial p_{i}\right)^{2}} \\
\psi_{2}^{E}\left(p_{i}, p_{j}, c_{i}\right)=\frac{\partial D_{i}}{\partial p_{j}}+\left(p_{i}-c_{i}\right) \frac{\partial^{2} D_{i}}{\partial p_{i} \partial p_{j}} \\
\psi_{3}^{E}\left(p_{i}, p_{j}, c_{i}\right)=-\frac{\partial D_{i}\left(p_{i}, p_{j}\right)}{\partial p_{i}}
\end{array}\right.
$$

Assumption 2 guarantees $(i)$ existence and unicity of an equilibrium $\left(p_{i}^{E}\left(c_{i}, c_{j}\right), p_{j}^{E}\left(c_{i}, c_{j}\right)\right)$, (ii) $\psi_{1}^{E}\left(p_{i}, p_{j}, c_{i}\right)<0$, since $\pi_{i}^{R}\left(p_{i}, p_{j}, c_{i}\right)$ is concave in $p_{i},(i i i) \psi_{2}^{E}\left(p_{i}^{E}\left(c_{i}, c_{j}\right), p_{j}^{E}\left(c_{i}, c_{j}\right), c_{i}\right)>$ 0 since prices are strategic complements, and $(i v)\left(\psi_{1}^{E}+\psi_{2}^{E}\right)\left(p_{i}^{E}\left(c_{i}, c_{j}\right), p_{j}^{E}\left(c_{i}, c_{j}\right), c_{i}\right)<$ 0 since the own price effect dominates. Thus:

$$
\Delta^{E}=\psi_{1}^{E}\left(p_{i}^{E}, p_{j}^{E}, c_{i}\right) \psi_{1}^{E}\left(p_{j}^{E}, p_{i}^{E}, c_{j}\right)-\psi_{2}^{E}\left(p_{i}^{E}, p_{j}^{E}, c_{i}\right) \psi_{2}^{E}\left(p_{j}^{E}, p_{i}^{E}, c_{j}\right)>0
$$

and

$$
\left\{\begin{array}{c}
\frac{\partial p_{i}^{E}}{\partial c_{i}}\left(c_{i}, c_{j}\right)=\frac{\partial D_{i}}{\partial p_{i}} \frac{\psi_{1}^{E}\left(p_{j}^{E}, p_{i}^{E}, c_{j}\right)}{\Delta^{E}}=\frac{\partial D_{i}}{\partial p_{i}} \frac{2 \frac{\partial D_{j}}{\partial p_{j}}+\left(p_{j}-c_{j}\right) \frac{\partial^{2} D_{j}}{\left(\partial p_{j}\right)^{2}}}{\Delta^{E}}>0 \\
\frac{\partial p_{j}^{E}}{\partial c_{i}}\left(c_{j}, c_{i}\right)=-\frac{\partial D_{i}}{\partial p_{i}} \frac{\psi_{2}^{E}\left(p_{j}^{E}, p_{i}^{E}, c_{j}\right)}{\Delta^{E}}=-\frac{\partial D_{i}}{\partial p_{i}} \frac{\frac{\partial D_{j}}{\partial p_{i}}+\left(p_{j}-c_{j}\right) \frac{\partial^{2} D_{j}}{\partial p_{i} \partial p_{j}}}{\Delta^{E}}>0
\end{array} .\right.
$$


Finally

$$
\begin{aligned}
\left(\frac{\partial p_{i}^{E}}{\partial c_{i}} \frac{\partial p_{j}^{E}}{\partial c_{j}}-\frac{\partial p_{j}^{E}}{\partial c_{i}} \frac{\partial p_{i}^{E}}{\partial c_{j}}\right)\left(c_{i}, c_{j}\right) & =\frac{\left[\begin{array}{c}
\psi_{1}^{E}\left(p_{j}^{E}, p_{i}^{E}, H_{j}\right) \psi_{3}^{E}\left(p_{i}^{E}, p_{j}^{E}, H_{i}\right) \\
\psi_{1}^{E}\left(p_{i}^{E}, p_{j}^{E}, H_{i}\right) \psi_{3}^{E}\left(p_{j}^{E}, p_{i}^{E}, H_{j}\right)
\end{array}\right)}{\left.-\left(\begin{array}{c}
\psi_{2}^{E}\left(p_{j}^{E}, p_{i}^{E}, H_{j}\right) \psi_{3}^{E}\left(p_{i}^{E}, p_{j}^{E}, H_{i}\right) \\
\psi_{2}^{E}\left(p_{i}^{E}, p_{j}^{E}, H_{i}\right) \psi_{3}^{E}\left(p_{j}^{E}, p_{i}^{E}, H_{j}\right)
\end{array}\right)\right]} \\
\left(\Delta^{E}\right)^{2} & \frac{\psi_{3}^{E}\left(p_{i}^{E}, p_{j}^{E}, H_{i}\right) \psi_{3}^{E}\left(p_{j}^{E}, p_{i}^{E}, H_{j}\right)}{\Delta^{E}}=\frac{\frac{\partial D_{i}}{\partial p_{i}} \frac{\partial D_{j}}{\partial p_{j}}}{\Delta^{E}}>0 .
\end{aligned}
$$

\section{B.2 Properties of the risk-adjusted expected cost (Lemma 2)}

The same derivation as for Cournot competition yields:

$$
\frac{\partial c_{i}}{\partial p_{i}}=\widehat{\mathbb{E}}\left[\rho\left(\pi_{i}\right) \frac{\partial \pi_{i}}{\partial p_{i}}\left(c_{i}-\tilde{c}\right)\right] .
$$

Then:

$$
\frac{\partial c_{i}}{\partial p_{i}}\left(p_{i}^{*}, p_{j}^{*}, H_{i}\right)=\left(\frac{\partial D_{i}}{\partial p_{i}} \widehat{\mathbb{E}}\left[\rho\left(\pi_{i}\right)\left(c_{i}-\tilde{c}\right)^{2}\right]\right)\left(p_{i}^{*}, p_{j}^{*}, H_{i}\right)<0
$$

since

$$
\frac{\partial \pi_{i}}{\partial p_{i}}\left(p_{i}^{*}, p_{j}^{*}, H_{i}\right)=\left(\left(c_{i}-\tilde{c}\right) \frac{\partial D_{i}}{\partial p_{i}}\right)\left(p_{i}^{*}, p_{j}^{*}, H_{i}\right)
$$

Then:

$$
\begin{aligned}
\frac{\partial c_{i}}{\partial p_{j}} & =\widehat{\mathbb{E}}\left[\rho\left(\pi_{i}\right) \frac{\partial \pi_{i}}{\partial p_{j}}\left(c_{i}-\tilde{c}\right)\right] \\
& =\frac{\partial D_{i}}{\partial p_{j}} \widehat{\mathbb{E}}\left[\rho\left(\pi_{i}\right)\left(p_{i}-\tilde{c}\right)\left(c_{i}-\tilde{c}\right)\right] \\
& =\frac{\partial D_{i}}{\partial p_{j}}\left\{\left(p_{i}-c_{i}\right) \widehat{\mathbb{E}}\left[\rho\left(\pi_{i}\right)\left(c_{i}-\tilde{c}\right)\right]+\widehat{\mathbb{E}}\left[\rho\left(\pi_{i}\right)\left(c_{i}-\tilde{c}\right)^{2}\right]\right\} .
\end{aligned}
$$

Thus:

$\frac{\partial c_{i}}{\partial p_{j}}\left(p_{i}^{*}, p_{j}^{*}, H_{i}\right)=\left(\frac{\partial D_{i}}{\partial p_{j}}\left\{\frac{D_{i}}{\frac{\partial D_{i}}{\partial p_{i}}} \widehat{\operatorname{cov}}\left[\rho\left(\pi_{i}\right), \tilde{c}\right]+\widehat{\mathbb{E}}\left[\rho\left(\pi_{i}\right)(\widehat{\mathbb{E}}[\tilde{c}]-\tilde{c})^{2}\right]\right\}\right)\left(p_{i}^{*}, p_{j}^{*}, H_{i}\right)$

Then:

$$
H_{i}>D_{i}\left(p_{i}^{*}, p_{j}^{*}\right) \Leftrightarrow \widehat{\operatorname{cov}}\left[\rho\left(\pi_{i}\right), \tilde{c}\right]<0 \Rightarrow \frac{\partial c_{i}}{\partial p_{j}}>0 .
$$


Finally:

$$
\begin{aligned}
\frac{\partial c_{i}}{\partial H_{i}} & =\widehat{\mathbb{E}}\left[\rho\left(\pi_{i}\right)(\tilde{c}-F)\left(c_{i}-\tilde{c}\right)\right] \\
& =-\widehat{\mathbb{E}}\left[\rho\left(\pi_{i}\right)\left(c_{i}-\tilde{c}\right)^{2}\right]+\left(c_{i}-F\right) \widehat{\mathbb{E}}\left[\rho\left(\pi_{i}\right)\left(c_{i}-\tilde{c}\right)\right] . \\
& =-\left(\widehat{\mathbb{E}}\left[\rho\left(\pi_{i}\right)\left(c_{i}-\tilde{c}\right)^{2}\right]+\frac{\operatorname{cov}\left[U^{\prime}\left(\pi_{i}\right), \tilde{c}\right] \cdot \widehat{\operatorname{cov}}\left[\rho\left(\pi_{i}\right), \tilde{c}\right]}{\mathbb{E}\left[U^{\prime}\left(\pi_{i}\right)\right]}\right) .
\end{aligned}
$$

Since $\rho($.$) and U^{\prime}($.$) are both non-increasing, \operatorname{cov}\left[U^{\prime}\left(\pi_{i}\right), \tilde{c}\right] \cdot \widehat{\operatorname{cov}}\left[\rho\left(\pi_{i}\right), \tilde{c}\right]>$ 0 , thus $\frac{\partial c_{i}}{\partial H_{i}}\left(p_{i}, p_{j}, H_{i}\right)<0$.

\section{B.3 Characterization of the equilibrium (Proposition 3)}

\section{B.3.1 Existence and unicity of equilibrium of the pricing game}

Since we ultimately focus on symmetric equilibria, we assume that $H_{i}$ and $H_{j}$ are close enough that $c\left(p_{i}, p_{j}, H_{i}\right)$ and $c\left(p_{j}, p_{i}, H_{j}\right)$ are close enough that the equilibrium - if it exists - is interior. The equilibrium prices are therefore solution of the system:

$$
\left\{\begin{array}{l}
p_{1}=p^{E}\left(c\left(p_{1}, p_{2}, H_{1}\right), c\left(p_{2}, p_{1}, H_{2}\right)\right) \\
p_{2}=p^{E}\left(c\left(p_{2}, p_{1}, H_{2}\right), c\left(p_{2}, p_{1}, H_{2}\right)\right)
\end{array} .\right.
$$

To apply Brouwer's fixed point theorem, we need only to establish that $\left(p_{i}, p_{j}\right)$ lies in a compact and convex set of $\mathbb{R}^{2}$. Since $\tilde{c} \leq \bar{c}$,

$$
c\left(p_{i}, p_{j}, H_{i}\right)=\frac{\mathbb{E}\left[U^{\prime}\left(\pi_{i}\left(p_{i}, p_{j}, H_{i}\right)\right) \tilde{c}\right]}{\mathbb{E}\left[U^{\prime}\left(\pi_{i}\left(p_{i}, p_{j}, H_{i}\right)\right)\right]} \leq \bar{c}
$$

for all $\left(p_{i}, p_{j}, H_{i}\right)$. Thus, since $p_{i}^{E}$ is increasing in $c_{i}$ and in $c_{j}$ :

$$
p^{E}\left(c\left(p_{i}, p_{j}, H_{i}\right), c\left(p_{j}, p_{i}, H_{j}\right)\right) \leq p^{E}(\bar{c}, \bar{c})
$$

Since $p_{i} \geq 0$ by definition, we can limit our search for a fixed point to the compact and convex set $\left[0, p^{E}(\bar{c}, \bar{c})\right]^{2}$. Brouwer's theorem then applies, and there exists a fixed point, i.e., an equilibrium. 
This equilibrium $\left(p_{1}^{*}, p_{2}^{*}\right)$ is unique if $\operatorname{Tr}<0$ and Det $>0$. Then:

$$
\begin{aligned}
& \operatorname{Tr}\left(p_{1}^{*}, p_{2}^{*}, H_{1}, H_{2}\right)=\left(\frac{\partial p_{i}^{E}}{\partial p_{i}}+\frac{\partial p_{j}^{E}}{\partial p_{j}}-2\right)\left(p_{1}^{*}, p_{2}^{*}, H_{1}, H_{2}\right) \\
& =\left(\frac{\partial p_{i}^{E}}{\partial c_{i}} \frac{\partial c_{i}}{\partial p_{i}}+\frac{\partial p_{j}^{E}}{\partial c_{j}} \frac{\partial c_{j}}{\partial p_{j}}+\underset{+}{+\frac{\partial p_{i}^{E}}{\partial c_{j}}} \frac{\partial c_{j}}{\partial p_{i}}+\underset{+}{\frac{\partial p_{j}^{E}}{\partial c_{j}}} \frac{\partial c_{j}}{\partial p_{j}}\right)\left(p_{1}^{*}, p_{2}^{*}, H_{1}, H_{2}\right)-2 \\
& =A\left(p_{1}^{*}, p_{2}^{*}, H_{1}, H_{2}\right)-2 \text {. }
\end{aligned}
$$

If $\rho$ is constant,

$$
\begin{aligned}
A\left(p_{1}, p_{2}, H_{1}, H_{2}\right)= & \frac{\partial D_{i}}{\partial p_{i}} \frac{\widehat{\mathbb{E}}\left[\rho\left(\pi_{i}\right)\left(c_{i}-\tilde{c}\right)^{2}\right]}{\Delta^{E}}\left(\frac{\partial D_{i}}{\partial p_{i}} \psi_{1}^{E}\left(p_{j}, p_{i}, c_{j}\right)-\frac{\partial D_{i}}{\partial p_{j}} \psi_{2}^{E}\left(p_{j}, p_{i}, c_{j}\right)\right) \\
& +\frac{\partial D_{j}}{\partial p_{j}} \frac{\widehat{\mathbb{E}}\left[\rho\left(\pi_{j}\right)\left(c_{j}-\tilde{c}\right)^{2}\right]}{\Delta^{E}}\left(\frac{\partial D_{j}}{\partial p_{j}} \psi_{1}^{E}\left(p_{i}, p_{j}, c_{i}\right)-\frac{\partial D_{j}}{\partial p_{i}} \psi_{2}^{E}\left(p_{i}, p_{j}, c_{i}\right)\right) .
\end{aligned}
$$

By Assumption 2, $\left(\psi_{1}^{E}+\psi_{2}^{E}\right)\left(p_{1}^{*}, p_{2}^{*}, H_{1}, H_{2}\right)<0$ and $\left(\frac{\partial D_{i}}{\partial p_{i}}+\frac{\partial D_{i}}{\partial p_{j}}\right)\left(p_{i}, p_{j}\right)<$ 0 , thus

$$
\left(\frac{\partial D_{i}}{\partial p_{i}} \psi_{1}^{E}-\frac{\partial D_{i}}{\partial p_{j}} \psi_{2}^{E}\right)\left(p_{1}^{*}, p_{2}^{*}, H_{1}, H_{2}\right)>0
$$

hence $A\left(p_{1}^{*}, p_{2}^{*}, H_{1}, H_{2}\right)<0$, hence $\operatorname{Tr}\left(p_{1}^{*}, p_{2}^{*}, H_{1}, H_{2}\right)<-2<0$.

$$
\begin{aligned}
\operatorname{Det}\left(p_{1}^{*}, p_{2}^{*}, H_{1}, H_{2}\right) & =\left(\frac{\partial p_{i}^{E}}{\partial p_{i}}-1\right)\left(\frac{\partial p_{j}^{E}}{\partial p_{j}}-1\right)-\frac{\partial p_{j}^{E}}{\partial p_{i}} \frac{\partial p_{i}^{E}}{\partial p_{j}} \\
& =\left(\frac{\partial p_{i}^{E}}{\partial c_{i}} \frac{\partial p_{j}^{E}}{\partial c_{j}}-\frac{\partial p_{i}^{E}}{\partial c_{j}} \frac{\partial p_{j}^{E}}{\partial c_{i}}\right)\left(\frac{\partial c_{i}}{\partial p_{i}} \frac{\partial c_{j}}{\partial p_{j}}-\frac{\partial c_{j}}{\partial p_{i}} \frac{\partial c_{i}}{\partial p_{j}}\right)-\operatorname{Tr}\left(p_{1}^{*}, p_{2}^{*}, H_{1}, H_{2}\right)-1
\end{aligned}
$$

Hence, if $\rho$ is constant,

$\frac{\partial p_{i}^{E}}{\partial c_{i}} \frac{\partial p_{j}^{E}}{\partial c_{j}}-\frac{\partial p_{i}^{E}}{\partial c_{j}} \frac{\partial p_{j}^{E}}{\partial c_{i}}=\widehat{\mathbb{E}}\left[\rho\left(\pi_{i}\right)\left(c_{i}-\tilde{c}\right)^{2}\right] \widehat{\mathbb{E}}\left[\rho\left(\pi_{j}\right)\left(c_{j}-\tilde{c}\right)^{2}\right]\left(\frac{\partial D_{i}}{\partial p_{i}} \frac{\partial D_{j}}{\partial p_{j}}-\frac{\partial D_{i}}{\partial p_{j}} \frac{\partial D_{j}}{\partial p_{i}}\right)>0$ and $\operatorname{Det}\left(p_{1}^{*}, p_{2}^{*}, H_{1}, H_{2}\right)>0$.

\section{B.3.2 Equilibrium of the hedging game}

The first order condition is

$$
\mathbb{E}\left[U^{\prime}\left(\pi_{i}\right)\left(\frac{\partial \pi_{i}}{\partial p_{i}} \frac{\partial p_{i}^{*}}{\partial H_{i}}+\frac{\partial \pi_{i}}{\partial p_{j}} \frac{\partial p_{j}^{*}}{\partial H_{i}}+\frac{\partial \pi_{i}}{\partial H_{i}}\right)\right]\left(p_{i}^{*}, p_{j}^{*}, H_{i}^{*}\right)=0
$$


Since $\frac{\partial \pi_{i}}{\partial p_{i}}\left(p_{i}^{*}, p_{j}^{*}, H_{i}\right)=0$ by construction, $\frac{\partial \pi_{i}}{\partial q_{j}}=\left(p_{i}-\tilde{c}\right) \frac{\partial D_{i}}{\partial p_{j}}$, and $\frac{\partial \pi_{i}}{\partial H_{i}}=$ $\tilde{c}-F$, this yields:

$$
\mathbb{E}\left[U^{\prime}\left(\pi_{i}\right)\left(\left(p_{i}-\tilde{c}\right) \frac{\partial D_{i}}{\partial p_{j}} \frac{\partial p_{j}^{*}}{\partial H_{i}}+\tilde{c}-F\right)\right]\left(p_{i}^{*}, p_{j}^{*}, H_{i}^{*}\right)=0 .
$$

Dividing by $\mathbb{E}\left[U^{\prime}\left(\pi_{i}\right)\right]>0$ yields

$$
\left(\left(p_{i}-c_{i}\right) \frac{\partial D_{i}}{\partial p_{j}} \frac{\partial p_{j}^{*}}{\partial H_{i}}+c_{i}-F\right)\left(p_{i}^{*}, p_{j}^{*}, H_{i}^{*}\right)=0
$$

Observing that

$$
\left(p_{i}-c_{i}+\frac{D_{i}}{\frac{\partial D_{i}}{\partial p_{i}}}\right)\left(p_{i}^{*}, p_{j}^{*}, H_{i}^{*}\right)=0
$$

yields equation (10).

\section{B.3.3 Sign of $\frac{\partial p_{j}^{*}}{\partial H_{i}}$ with constant absolute risk aversion}

$$
\begin{aligned}
& \psi_{1}\left(p_{i}, p_{j}, H_{i}\right)=\psi_{1}^{E}\left(p_{i}, p_{j}, c_{i}\left(p_{i}, p_{j}, H_{i}\right)\right)-\frac{\partial D_{i}}{\partial p_{i}} \frac{\partial c_{i}}{\partial p_{i}}<0, \\
& \psi_{2}\left(p_{i}, p_{j}, H_{i}\right)=\psi_{2}^{E}\left(p_{i}, p_{j}, c_{i}\left(p_{i}, p_{j}, H_{i}\right)\right)-\frac{\partial D_{i}}{\partial p_{i}} \frac{\partial c_{i}}{\partial p_{j}}>0,
\end{aligned}
$$

and

$$
\psi_{3}\left(p_{i}, p_{j}, H_{i}\right)=\left(-\frac{\partial D_{i}}{\partial p_{i}} \frac{\partial c_{i}}{\partial H_{i}}\right)\left(p_{i}, p_{j}, H_{i}\right)<0
$$

Then:

$$
\begin{aligned}
\Delta= & \Delta^{E}-\frac{\partial D_{i}}{\partial p_{i}} \widehat{\mathbb{E}}\left[\rho\left(\pi_{i}\right)\left(c_{i}-\tilde{c}\right)^{2}\right]\left(\frac{\partial D_{i}}{\partial p_{i}} \psi_{1}^{E}\left(p_{j}^{*}, p_{i}^{*}, c_{j}\right)-\frac{\partial D_{i}}{\partial p_{j}} \psi_{2}^{E}\left(p_{j}^{*}, p_{i}^{*}, c_{j}\right)\right) \\
& -\frac{\partial D_{j}}{\partial p_{j}} \widehat{\mathbb{E}}\left[\rho\left(\pi_{j}\right)\left(c_{j}-\tilde{c}\right)^{2}\right]\left(\frac{\partial D_{j}}{\partial p_{j}} \psi_{1}^{E}\left(p_{i}^{*}, p_{j}^{*}, c_{i}\right)-\frac{\partial D_{j}}{\partial p_{i}} \psi_{2}^{E}\left(p_{i}^{*}, p_{j}^{*}, c_{i}\right)\right) \\
& +\frac{\partial D_{i}}{\partial p_{i}} \frac{\partial D_{j}}{\partial p_{j}} \widehat{\mathbb{E}}\left[\rho\left(\pi_{i}\right)\left(c_{i}-\tilde{c}\right)^{2}\right] \widehat{\mathbb{E}}\left[\rho\left(\pi_{j}\right)\left(c_{j}-\tilde{c}\right)^{2}\right]\left(\frac{\partial D_{i}}{\partial p_{i}} \frac{\partial D_{j}}{\partial p_{j}}-\frac{\partial D_{j}}{\partial p_{i}} \frac{\partial D_{i}}{\partial p_{j}}\right) \\
> & 0
\end{aligned}
$$

Thus, at the symmetric equilibrium,

$$
\frac{\partial p_{j}^{*}}{\partial H_{i}}\left(H^{*}, H^{*}\right)=\frac{\psi_{2}\left(p^{*}, p^{*}, H^{*}\right)}{\Delta} \psi_{3}\left(p^{*}, p^{*}, H^{*}\right)<0 .
$$

\section{B.3.4 Equilibrium price}

$$
\frac{\partial p_{j}^{*}}{\partial H_{i}}\left(H^{*}, H^{*}\right)<0 \Leftrightarrow c\left(p^{*}, p^{*}, H^{*}\right)>F .
$$


Consider $\bar{p}(c)$ defined implicitly by

$$
(\bar{p}(c)-c) \frac{\partial D(\bar{p}(c), \bar{p}(c))}{\partial p_{1}}+D(\bar{p}(c), \bar{p}(c))=0
$$

where $\frac{\partial D}{\partial p_{1}}$ is the derivative of $D(.,$.$) with respect to its first argument.$

$$
\frac{d \bar{p}}{d c}=\frac{\frac{\partial D_{1}}{\partial p_{1}}}{2 \frac{\partial D}{\partial p_{1}}+\frac{\partial D}{\partial p_{2}}+(\bar{p}(c)-c)\left(\frac{\partial^{2} D}{\left(\partial p_{1}\right)^{2}}+\frac{\partial^{2} D}{\partial p_{2} \partial p_{1}}\right)}>0
$$

since $\frac{\partial D_{1}}{\partial p_{1}}+\frac{\partial D_{1}}{\partial p_{2}}<0$ and $\frac{\partial^{2} D_{1}}{\left(\partial p_{1}\right)^{2}}+\frac{\partial^{2} D_{1}}{\partial p_{2} \partial p_{1}} \leq 0$ by Assumption 2. Thus,

$$
c\left(p^{*}, p^{*}, H^{*}\right)>F \Leftrightarrow p^{*}=\bar{p}\left(c\left(p^{*}, p^{*}, H^{*}\right)\right)>\bar{p}(F)=p^{E}(F, F) .
$$

\section{Robustness analysis: proof of Propositions 4 and 5}

\section{C.1 Sufficient condition for the unicity of the equilibrium of the production game}

We first derive a sufficient condition for $\operatorname{Tr}\left(q_{1}^{*}, q_{2}^{*}, H_{1}, H_{2}\right) \leq-k$, for $k \in$ $(1,2)$. From the analysis above,

$$
\begin{aligned}
& \operatorname{Tr}\left(q_{1}^{*}, q_{2}^{*}, H_{1}, H_{2}\right)=\left(\frac{\partial q_{i}^{E}}{\partial c_{i}} \frac{\partial c_{i}}{\partial q_{i}}+\frac{\partial q_{j}^{E}}{\partial c_{j}} \frac{\partial c_{j}}{\partial q_{j}}+\frac{\partial q_{i}^{E}}{\partial c_{j}} \frac{\partial c_{j}}{\partial q_{i}}+\frac{\partial q_{j}^{E}}{\partial c_{i}} \frac{\partial c_{i}}{\partial q_{j}}\right)\left(q_{1}^{*}, q_{2}^{*}, H_{1}, H_{2}\right)-2 . \\
& \frac{\partial q_{i}^{E}}{\partial c_{j}} \frac{\partial c_{j}}{\partial q_{i}}+\frac{\partial q_{j}^{E}}{\partial c_{i}} \frac{\partial c_{i}}{\partial q_{j}}=-\frac{\left(P^{\prime}\left(Q^{*}\right)+q_{i}^{*} P^{\prime \prime}\left(Q^{*}\right)\right) \frac{\partial c_{j}}{\partial q_{i}}+\left(P^{\prime}\left(Q^{*}\right)+q_{j}^{*} P^{\prime \prime}\left(Q^{*}\right)\right) \frac{\partial c_{i}}{\partial q_{j}}}{P^{\prime}\left(Q^{*}\right)\left(3 P^{\prime}\left(Q^{*}\right)+Q^{*} P^{\prime \prime}\left(Q^{*}\right)\right)}
\end{aligned}
$$

Thus:

$$
-\frac{\left(P^{\prime}\left(Q^{*}\right)+q_{i}^{*} P^{\prime \prime}\left(Q^{*}\right)\right) \frac{\partial c_{j}}{\partial q_{i}}+\left(P^{\prime}\left(Q^{*}\right)+q_{j}^{*} P^{\prime \prime}\left(Q^{*}\right)\right) \frac{\partial c_{i}}{\partial q_{j}}}{P^{\prime}\left(Q^{*}\right)\left(3 P^{\prime}\left(Q^{*}\right)+Q^{*} P^{\prime \prime}\left(Q^{*}\right)\right)} \leq 2-k \Rightarrow \operatorname{Tr}\left(q_{1}^{*}, q_{2}^{*}, H_{1}, H_{2}\right) \leq-k
$$

The inequality is equivalent to:

$$
\begin{aligned}
& -\left(P^{\prime}\left(Q^{*}\right)+q_{i}^{*} P^{\prime \prime}\left(Q^{*}\right)\right) \frac{\partial c_{j}}{\partial q_{i}}-\left(P^{\prime}\left(Q^{*}\right)+q_{j}^{*} P^{\prime \prime}\left(Q^{*}\right)\right) \frac{\partial c_{i}}{\partial q_{j}} \\
\leq & (2-k) P^{\prime}\left(Q^{*}\right)\left(3 P^{\prime}\left(Q^{*}\right)+Q^{*} P^{\prime \prime}\left(Q^{*}\right)\right)
\end{aligned}
$$


Suppose first $P^{\prime \prime}(Q)>0,-\left(P^{\prime}\left(Q^{*}\right)+q_{i}^{*} P^{\prime \prime}\left(Q^{*}\right)\right)<-P^{\prime}\left(Q^{*}\right)$. Since $\left|\frac{\partial c_{i}}{\partial q_{j}}\right| \leq\left|P^{\prime}\left(Q^{*}\right)\right| \bar{q}^{E} R$, the left hand side is bounded above by

$$
\left(-P^{\prime}\left(Q^{*}\right)\right)\left(\left|\frac{\partial c_{i}}{\partial q_{j}}\right|+\left|\frac{\partial c_{j}}{\partial q_{i}}\right|\right) \leq 2\left(P^{\prime}\left(Q^{*}\right)\right)^{2} \bar{q}^{E} R
$$

Since $\frac{Q^{*} P^{\prime \prime}\left(Q^{*}\right)}{\left(-P^{\prime}\left(Q^{*}\right)\right)} \leq 1$ by Assumption 1 , the right hand side is bounded below by

$$
2(2-k)\left(P^{\prime}\left(Q^{*}\right)\right)^{2} \leq(2-k)\left(P^{\prime}\left(Q^{*}\right)\right)^{2}\left(3+\frac{Q^{*} P^{\prime \prime}\left(Q^{*}\right)}{P^{\prime}\left(Q^{*}\right)}\right) .
$$

Thus,

$$
\bar{q}^{E} R \leq(2-k) \Rightarrow \operatorname{Tr}\left(q_{1}^{*}, q_{2}^{*}, H_{1}, H_{2}\right) \leq-k .
$$

We now derive a sufficient condition for $\operatorname{Det}\left(q_{1}^{*}, q_{2}^{*}, H_{1}, H_{2}\right)>0$. From the analysis above,

$\operatorname{Det}=-\operatorname{Tr}-1+\left(\frac{1}{P^{\prime}\left(Q^{*}\right)\left(3 P^{\prime}\left(Q^{*}\right)+Q^{*} P^{\prime \prime}\left(Q^{*}\right)\right)}\left(\frac{\partial c_{i}}{\partial q_{i}} \frac{\partial c_{j}}{\partial q_{j}}-\frac{\partial c_{j}}{\partial q_{i}} \frac{\partial c_{i}}{\partial q_{j}}\right)\right)$.

Thus,

$$
\frac{\partial c_{j}}{\partial q_{i}} \frac{\partial c_{i}}{\partial q_{j}}<-(\operatorname{Tr}+1) P^{\prime}\left(Q^{*}\right)\left(3 P^{\prime}\left(Q^{*}\right)+Q^{*} P^{\prime \prime}\left(Q^{*}\right)\right) \Rightarrow \text { Det }>0 .
$$

The left hand side is bounded above by $\left(P^{\prime}\left(Q^{*}\right)\right)^{2}\left(\bar{q}^{E} R\right)^{2}$. The right hand side is bounded below by $2(k-1)\left(P^{\prime}\left(Q^{*}\right)\right)^{2}>0$. Thus,

$$
\bar{q}^{E} R \leq \sqrt{2(k-1)} \Rightarrow \operatorname{Det}\left(q_{1}^{*}, q_{2}^{*}, H_{1}, H_{2}\right)>0 .
$$

Thus, for any $k \in(1,2)$,

$\bar{q}^{E} R \leq \min (\sqrt{2(k-1)},(2-k)) \Rightarrow \operatorname{Det}\left(q_{1}^{*}, q_{2}^{*}, H_{1}, H_{2}\right)>0$ and $\operatorname{Tr}\left(q_{1}^{*}, q_{2}^{*}, H_{1}, H_{2}\right) \leq-k$.

We choose $k^{*}=(3-\sqrt{3})=\max _{k \in(1,2)}(\min (\sqrt{2(k-1)},(2-k)))$, thus, if $P^{\prime \prime}(Q) \geq 0$

$$
\bar{q}^{E} R \leq(\sqrt{3}-1) \Rightarrow \operatorname{Det}\left(q_{1}^{*}, q_{2}^{*}, H_{1}, H_{2}\right)>0 \text { and } \operatorname{Tr}\left(q_{1}^{*}, q_{2}^{*}, H_{1}, H_{2}\right) \leq-k
$$


The same derivations for $P^{\prime \prime}(Q)<0$ yield $\bar{q}^{E} R \leq(2 \sqrt{3}-3) \Rightarrow \operatorname{Det}\left(q_{1}^{*}, q_{2}^{*}, H_{1}, H_{2}\right)>0$ and $\operatorname{Tr}\left(q_{1}^{*}, q_{2}^{*}, H_{1}, H_{2}\right) \leq-k$, and for $P^{\prime \prime}(Q)=0$

$$
\bar{q}^{E} R \leq 1 \Rightarrow \operatorname{Det}\left(q_{1}^{*}, q_{2}^{*}, H_{1}, H_{2}\right)>0 \text { and } \operatorname{Tr}\left(q_{1}^{*}, q_{2}^{*}, H_{1}, H_{2}\right) \leq-k
$$

\section{C.2 Sufficient condition for $\frac{\partial q_{j}^{*}}{\partial H_{i}}\left(H^{*}, H^{*}\right)<0$}

Lemma 3 Consider a symmetric equilibrium, $H_{i}=H_{j}=H^{*}$, and $q_{i}=q_{j}=$ $q^{*}\left(H^{*}, H^{*}\right)$.

$$
\left(P^{\prime}(Q)-\frac{\partial c_{i}}{\partial q_{i}}+\frac{\partial c_{i}}{\partial q_{j}}\right)\left(q^{*}, q^{*}, H^{*}\right)<0 \Leftrightarrow \frac{\partial q_{j}^{*}}{\partial H_{i}}\left(H^{*}, H^{*}\right)<0 .
$$

Proof. We first prove that

$$
\begin{aligned}
& \left(P^{\prime}(Q)-\frac{\partial c_{i}}{\partial q_{i}}+\frac{\partial c_{i}}{\partial q_{j}}\right)\left(q^{*}, q^{*}, H^{*}\right)<0 \Rightarrow \frac{\partial q_{j}^{*}}{\partial H_{i}}\left(H^{*}, H^{*}\right)<0 . \\
\Delta= & \psi_{1}\left(q_{i}^{*}, q_{j}^{*}, H_{i}\right) \psi_{1}\left(q_{j}^{*}, q_{i}^{*}, H_{j}\right)-\psi_{2}\left(q_{i}^{*}, q_{j}^{*}, H_{i}\right) \psi_{2}\left(q_{j}^{*}, q_{i}^{*}, H_{j}\right) \\
= & \left(2 P^{\prime}\left(Q^{*}\right)+q_{i}^{*} P^{\prime \prime}\left(Q^{*}\right)-\frac{\partial c_{i}}{\partial q_{i}}\right)\left(2 P^{\prime}\left(Q^{*}\right)+q_{j}^{*} P^{\prime \prime}\left(Q^{*}\right)-\frac{\partial c_{j}}{\partial q_{j}}\right) \\
& -\left(P^{\prime}\left(Q^{*}\right)+q_{i}^{*} P^{\prime \prime}\left(Q^{*}\right)-\frac{\partial c_{i}}{\partial q_{j}}\right)\left(P^{\prime}\left(Q^{*}\right)+q_{j}^{*} P^{\prime \prime}\left(Q^{*}\right)-\frac{\partial c_{j}}{\partial q_{i}}\right) \\
= & -P^{\prime}\left(Q^{*}\right)\left(\frac{\partial c_{i}}{\partial q_{i}}+\frac{\partial c_{j}}{\partial q_{j}}-P^{\prime}\left(Q^{*}\right)\right)+\left(P^{\prime}\left(Q^{*}\right)-\frac{\partial c_{i}}{\partial q_{i}}+\frac{\partial c_{i}}{\partial q_{j}}\right)\left(P^{\prime}\left(Q^{*}\right)+q_{j}^{*} P^{\prime \prime}\left(Q^{*}\right)\right) \\
& +\left(P^{\prime}\left(Q^{*}\right)-\frac{\partial c_{j}}{\partial q_{j}}+\frac{\partial c_{i}}{\partial q_{j}}\right)\left(P^{\prime}\left(Q^{*}\right)+q_{i}^{*} P^{\prime \prime}\left(Q^{*}\right)\right)
\end{aligned}
$$

Thus,

$$
\left(P^{\prime}(Q)-\frac{\partial c_{i}}{\partial q_{i}}+\frac{\partial c_{i}}{\partial q_{j}}\right)\left(q_{i}^{*}, q_{j}^{*}, H_{i}, H_{j}\right)<0 \text { for } i=1,2 \Rightarrow \Delta>0 .
$$

Thus, since $\psi_{3}\left(q_{i}, q_{j}, H_{i}\right)>0$,

$\psi_{2}\left(q^{*}, q^{*}, H^{*}\right)=\left(P^{\prime}(Q)+q_{i} P^{\prime \prime}(Q)-\frac{\partial c_{i}}{\partial q_{j}}\right)\left(q^{*}, q^{*}, H^{*}\right)<0 \Leftrightarrow \frac{\partial q_{j}^{*}}{\partial H_{i}}\left(H^{*}, H^{*}\right)$.

To complete the proof, we show that $\psi_{2}\left(q^{*}, q^{*}, H^{*}\right)<0$. Suppose $\psi_{2}\left(q^{*}, q^{*}, H^{*}\right)>$ 
0 , then

$$
\frac{\partial q_{j}^{*}}{\partial H_{i}}\left(H^{*}, H^{*}\right)>0 \Leftrightarrow H^{*}<q^{*} \Leftrightarrow \frac{\partial c_{i}}{\partial q_{j}}>0 \Rightarrow \psi_{2}\left(q^{*}, q^{*}, H^{*}\right)<0
$$

which is a contradiction.

Reciprocally,

$\frac{\partial q_{j}^{*}}{\partial H_{i}}\left(H^{*}, H^{*}\right)<0 \Leftrightarrow H^{*}>q^{*} \Leftrightarrow \frac{\partial c_{i}}{\partial q_{j}}<0 \Rightarrow\left(P^{\prime}(Q)-\frac{\partial c_{i}}{\partial q_{i}}+\frac{\partial c_{i}}{\partial q_{j}}\right)\left(q^{*}, q^{*}, H^{*}\right)<0$

Thus:

$$
\left|\frac{\partial c_{i}}{\partial q_{j}}\right| \leq\left|P^{\prime}(Q)\right| \Rightarrow \frac{\partial q_{j}^{*}}{\partial H_{i}}\left(H^{*}, H^{*}\right)<0
$$

$\Rightarrow$

$$
\bar{q}^{E} R \leq 1 \Rightarrow \frac{\partial q_{j}^{*}}{\partial H_{i}}\left(H^{*}, H^{*}\right)<0 .
$$

\section{C.3 Global sufficient condition for quantity competition}

Since $(\sqrt{3}-1)<1$ and $(2 \sqrt{3}-3)<1$, the sufficient condition for unicity of the equilibrium and $\frac{\partial q_{j}^{*}}{\partial H_{i}}\left(H^{*}, H^{*}\right)<0$ is $\bar{q}^{E} R \leq(\sqrt{3}-1)$ if $P^{\prime \prime}(Q)>0$, $\bar{q}^{E} R \leq(2 \sqrt{3}-3)$ if $P^{\prime \prime}(Q)<0$, and $\bar{q}^{E} R \leq 1$ if $P^{\prime \prime}(Q)=1$.

C.4 Sufficient condition for $\frac{\partial p_{j}^{*}}{\partial H_{i}}\left(H^{*}, H^{*}\right)<0$ (Proof of Proposition 5)

Lemma 4

$$
\left(\psi_{1}+\psi_{2}\right)\left(p^{*}, p^{*}, H^{*}\right)<0 \Rightarrow \frac{\partial p_{j}^{*}}{\partial H_{i}}\left(H^{*}, H^{*}\right)<0
$$

Proof. Suppose $\left(\psi_{1}+\psi_{2}\right)\left(p^{*}, p^{*}, H^{*}\right)<0$. Suppose first $\psi_{2}\left(p^{*}, p^{*}, H^{*}\right)>0$.

Then, $\left(\psi_{1}-\psi_{2}\right)\left(p^{*}, p^{*}, H^{*}\right)<0$ since $\psi_{1}\left(p^{*}, p^{*}, H^{*}\right)<0$, hence

$$
\frac{\partial p_{j}^{*}}{\partial H_{i}}\left(H^{*}, H^{*}\right)=(\underbrace{\frac{\overbrace{\psi_{2}}^{+} \tau_{\psi_{3}}^{-}}{(\underbrace{}_{1}+\psi_{2})\left(\psi_{1}-\psi_{2}\right)}}_{-})\left(p^{*}, p^{*}, H^{*}\right)<0 .
$$


Suppose $\psi_{2}\left(p^{*}, p^{*}, H^{*}\right)<0$. Suppose first $\left(\psi_{1}-\psi_{2}\right)\left(p^{*}, p^{*}, H^{*}\right)>0$. Then,

$$
\frac{\partial p_{j}^{*}}{\partial H_{i}}\left(H^{*}, H^{*}\right)=(\underbrace{\frac{\overbrace{\psi_{2} \psi_{3}}^{-}}{(\underbrace{\left.\psi_{1}+\psi_{2}\right)\left(\psi_{1}-\psi_{2}\right)}_{1}}}_{-})\left(p_{+}^{*}, p^{*}, H^{*}\right)<0 .
$$

Suppose now $\left(\psi_{1}-\psi_{2}\right)\left(p^{*}, p^{*}, H^{*}\right)<0$. Then,

$$
\frac{\partial p_{j}^{*}}{\partial H_{i}}\left(H^{*}, H^{*}\right)=(\underbrace{\frac{\overbrace{\psi_{2} \psi_{3}}^{-}-}{\left(\psi_{1}+\psi_{2}\right)\left(\psi_{1}-\psi_{2}\right)}}_{-})\left(p^{*}, p^{*}, H^{*}\right)>0
$$

hence $\frac{\partial p_{j}^{*}}{\partial H_{i}}\left(H_{i}, H_{j}\right)>0$. Then:

$$
H_{i}>D_{i}\left(p_{i}^{*}, p_{j}^{*}\right) \Rightarrow \frac{\partial c_{i}}{\partial p_{j}}\left(p^{*}, p^{*}, H^{*}\right)>0 \Rightarrow \psi_{2}\left(p^{*}, p^{*}, H^{*}\right)>0
$$

which is a contradiction. Hence, $\psi_{1}\left(p^{*}, p^{*}, H^{*}\right)<\psi_{2}\left(p^{*}, p^{*}, H^{*}\right)<0$ is not possible. Hence,

$$
\left(\psi_{1}+\psi_{2}\right)\left(p^{*}, p^{*}, H^{*}\right)<0 \Rightarrow \frac{\partial p_{j}^{*}}{\partial H_{i}}\left(p^{*}, p^{*}, H^{*}\right)<0
$$

which completes the proof.

Then,

$$
\begin{aligned}
\left(\frac{\partial c_{i}}{\partial p_{i}}+\frac{\partial c_{i}}{\partial p_{j}}\right)\left(p_{i}, p_{j}, H_{i}\right)= & \widehat{\mathbb{E}}\left[\rho\left(\pi_{i}\right)\left(c_{i}-\tilde{c}\right)\left(\frac{\partial \pi_{i}}{\partial p_{i}}+\frac{\partial \pi_{i}}{\partial p_{j}}\right)\right] \\
= & \widehat{\mathbb{E}}\left[\rho\left(\pi_{i}\right)\left(c_{i}-\tilde{c}\right)\left(D_{i}+\left(p_{i}-\tilde{c}\right)\left(\frac{\partial D_{i}}{\partial p_{i}}+\frac{\partial D_{i}}{\partial p_{j}}\right)\right)\right] \\
= & D_{i} \widehat{\mathbb{E}}\left[\rho\left(\pi_{i}\right)\left(c_{i}-\tilde{c}\right)\right] \\
& +\left(\frac{\partial D_{i}}{\partial p_{i}}+\frac{\partial D_{i}}{\partial p_{j}}\right)\left\{\left(p_{i}-c_{i}\right) \widehat{\mathbb{E}}\left[\rho\left(\pi_{i}\right)\left(c_{i}-\tilde{c}\right)\right]+\widehat{\mathbb{E}}\left[\rho\left(\pi_{i}\right)\left(c_{i}-\tilde{c}\right)^{2}\right]\right\},
\end{aligned}
$$

and

$$
\left(\frac{\partial c_{i}}{\partial p_{i}}+\frac{\partial c_{i}}{\partial p_{j}}\right)\left(p_{i}^{*}, p_{j}^{*}, H_{i}\right)=\left(\begin{array}{c}
\frac{\partial D_{i}}{\partial p_{j}}\left(p_{i}-c_{i}\right) \widehat{\mathbb{E}}\left[\rho\left(\pi_{i}\right)\left(c_{i}-\tilde{c}\right)\right] \\
+\left(\frac{\partial D_{i}}{\partial p_{i}}+\frac{\partial D_{i}}{\partial p_{j}}\right) \widehat{\mathbb{E}}\left[\rho\left(\pi_{i}\right)\left(c_{i}-\tilde{c}\right)^{2}\right]
\end{array}\right)\left(p_{i}^{*}, p_{j}^{*}, H_{i}\right) .
$$


Then,

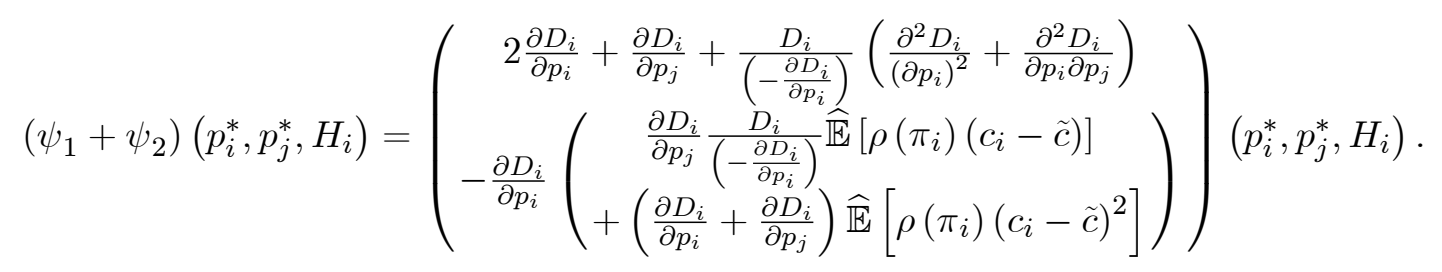

Thus,

$\widehat{\mathbb{E}}\left[\rho\left(\pi_{i}\right)\left(c_{i}-\tilde{c}\right)\right]<\left(\frac{-\left(\frac{\partial^{2} \pi_{i}^{R}}{\left(\partial p_{i}\right)^{2}}+\frac{\partial^{2} \pi_{i}^{R}}{\partial p_{i} \partial p_{j}}\right)}{\frac{\partial D_{i}}{\partial p_{j}} D_{i}}\right)\left(p^{*}, p^{*}, H^{*}\right) \Rightarrow \frac{\partial p_{j}^{*}}{\partial H_{i}}\left(H^{*}, H^{*}\right)<0$.

Thus,

$$
R \leq m \Rightarrow \frac{\partial p_{j}^{*}}{\partial H_{i}}\left(H^{*}, H^{*}\right)<0 .
$$

\section{Strategic incentives to commit (Proposition 6)}

\section{D.1 Comparing $V(C, N C)$ and $V(N C, N C)$ if firms compete in price}

Suppose firm 2 plays $N C$, while firm 1 plays $C$. At $t=2$, firm 2 chooses $\bar{H}_{2}=$ $D_{2}\left(p_{2}, p_{1}\right)$. At $t=1$, firms simultaneously select prices $\left(\bar{p}_{1}\left(H_{1}\right), \bar{p}_{2}\left(H_{1}\right)\right)$ that solve:

$$
\left\{\begin{array}{c}
D_{1}\left(\bar{p}_{1}, \bar{p}_{2}\right)+\left(\bar{p}_{1}-c_{1}\left(p_{1}, p_{2}, H_{1}\right)\right) \frac{\partial D_{1}}{\partial p_{1}}\left(\bar{p}_{1}, \bar{p}_{2}\right)=0 \\
D_{2}\left(\bar{p}_{2}, \bar{p}_{1}\right)+\left(\bar{p}_{2}-F\right) \frac{\partial D_{2}}{\partial p_{2}}\left(\bar{p}_{2}, \bar{p}_{1}\right)=0
\end{array}\right.
$$

At $t=0$, firm 1 selects $\bar{H}_{1}$ that maximizes $\mathbb{E}\left[U\left(\pi_{1}\left(\bar{p}_{1}\left(H_{1}\right), \bar{p}_{2}\left(H_{1}\right), H_{1}\right)\right)\right]$. As in the Cournot case, if firm 1 chooses $H_{1}=D\left(p^{E}(F, F), p^{E}(F, F)\right)$, $p_{1}=p_{2}=p^{E}(F, F)$ is a solution of the system, hence the unique equilibrium. Both firms receive $V(N C, N C)$. Thus, $V(C, N C) \geq V(N C, N C)$.

Then

$$
\frac{d V_{1}}{d H_{1}}\left(D\left(p^{E}(F, F), p^{E}(F, F)\right)\right)=\frac{\partial D_{1}}{\partial p_{2}}\left(p^{E}(F, F)-F\right) \frac{\partial \bar{p}_{2}}{\partial H_{1}} \mathbb{E}\left[U^{\prime}\left(\pi_{1}\right)\right]<0 .
$$

Thus, if the firm hedges $\left(\frac{1}{2}-\varepsilon\right)$ where $\varepsilon>0$ is arbitrarily small, by continuity, $V_{1}\left(\frac{1}{2}-\varepsilon\right)>V_{1}\left(\frac{1}{2}\right)$. Thus, $V(C, N C)>V(N C, N C)$.

\section{D.2 Comparing $V(C, C)$ and $V(N C, N C)$ if firms compete in} quantity

$V(C, C)=\mathbb{E}\left[U\left(\left(P\left(Q^{*}\right)-F\right) \frac{Q^{*}}{2}+\left(H^{*}-Q^{*}\right)(\omega-F)\right)\right]<U\left(\left(P\left(Q^{*}\right)-F\right) \frac{Q^{*}}{2}\right)$ 
since $U($.$) is concave, and$

$$
V(N C, N C)=U\left(\left(P\left(2 q^{E}(F, F)\right)-F\right) q^{E}(F, F)\right) .
$$

For $x \geq 0$, denote

$$
f(x)=(P(2 x)-F) x .
$$

Condition 1 implies that $f($.$) is globally concave and admits a unique maxi-$ mum $x^{*}$ defined by:

$$
f^{\prime}\left(x^{*}\right)=P\left(2 x^{*}\right)-F+2 x^{*} P^{\prime}\left(2 x^{*}\right)=0 .
$$

Then,

$$
\begin{aligned}
f^{\prime}\left(q^{E}(F, F)\right) & =\left(-q^{E}(F, F) P^{\prime}\left(2 q^{E}(F, F)\right)+2 q^{E}(F, F) P^{\prime}\left(2 q^{E}(F, F)\right)\right) \\
& =q^{E}(F, F) P^{\prime}\left(2 q^{E}(F, F)\right) \\
& <0
\end{aligned}
$$

hence $q^{E}(F, F)>x^{*}$. Then, $f\left(q^{E}(F, F)\right)>f\left(q^{*}\right)$ since $q^{*}>q^{E}(F, F)$ and $f($.$) is decreasing for x \geq x^{*}$. Thus:

$$
V(C, C)<U\left(f\left(q^{*}\right)\right)<U\left(f\left(q^{E}(F, F)\right)\right)=V(N C, N C) .
$$

\section{D.3 Hotelling competition}

\section{D.3.1 Comparing $V(C, C)$ and $V(N C, N C)$}

Under the conditions of Proposition 6

$$
\begin{aligned}
c_{i}\left(p_{i}, p_{j}, H_{i}\right) & =F+\rho \sigma^{2}\left(D_{i}\left(p_{i}, p_{j}\right)-H_{i}\right) \\
& =F+\rho \sigma^{2}\left(\frac{p_{j}-p_{i}}{2 t}+\frac{1}{2}-H_{i}\right)
\end{aligned}
$$

Thus, for $i=1,2$, the first-order conditions (9) are

$$
\begin{aligned}
D_{i}\left(p_{i}, p_{j}\right)+\frac{\partial D_{i}}{\partial p_{i}}\left(p_{i}, p_{j}\right)\left(p_{i}-\left(F+\rho \sigma^{2}\left(D_{i}\left(p_{i}, p_{j}\right)-H_{i}\right)\right)\right. & =0 \\
\Leftrightarrow \quad \frac{1}{2}+\frac{p_{j}-p_{i}}{2 t}-\frac{1}{2 t}\left(p_{i}-\left(F+\rho \sigma^{2}\left(\frac{p_{j}-p_{i}}{2 t}+\frac{1}{2}-H_{i}\right)\right)\right) & =0
\end{aligned}
$$


$\Leftrightarrow$

$$
\left(2+\frac{\rho \sigma^{2}}{2 t}\right) p_{i}-\left(1+\frac{\rho \sigma^{2}}{2 t}\right) p_{j}=t+F+\rho \sigma^{2}\left(\frac{1}{2}-H_{i}\right)
$$

which yield equilibrium prices for $i=1,2$

$$
\begin{aligned}
p_{i}^{*}\left(H_{i}, H_{j}\right) & =t+F+\frac{\rho \sigma^{2}}{2}\left(1-\frac{\left(4 t+\rho \sigma^{2}\right) H_{i}+\left(2 t+\rho \sigma^{2}\right) H_{j}}{3 t+\rho \sigma^{2}}\right) \\
& =F+\left(1+\frac{1}{2 a}\left(1-\frac{(1+4 a) H_{i}+(1+2 a) H_{j}}{1+3 a}\right)\right) t
\end{aligned}
$$

where $a=\frac{t}{\rho \sigma^{2}}$. Thus:

$$
\frac{\partial p_{j}^{*}}{\partial H_{i}}=-\frac{1+2 a}{2 a(1+3 a)} t<0 .
$$

The first-order conditions (10) become

$$
\left(\rho \sigma^{2}\left(D_{i}\left(p_{i}^{*}, p_{j}^{*}\right)-H_{i}\right)+D_{i}\left(p_{i}^{*}, p_{j}^{*}\right) \frac{\partial p_{j}^{*}}{\partial H_{i}}\right)\left(H_{i}^{*}, H_{j}^{*}\right)=0
$$

since $c_{i}=F+\rho \sigma^{2}\left(D_{i}\left(p_{i}, p_{j}\right)-H_{i}\right)$ and $\frac{\partial D_{i}}{\partial p_{j}}\left(p_{i}, p_{j}\right)=-\frac{\partial D_{i}}{\partial p_{i}}\left(p_{i}, p_{j}\right)=\frac{1}{2 t}$.

Consider now a symmetric equilibrium: $H_{i}^{*}=H_{j}^{*}=H^{*}$, hence $p_{i}^{*}=p_{j}^{*}=$ $p^{*}$. Since the equilibrium is symmetric, $D_{i}\left(p_{i}^{*}, p_{j}^{*}\right)=\frac{1}{2}$. Thus, the first-order conditions (10) further simplify to:

$$
\frac{1}{2}-H^{*}=\frac{1+2 a}{4(1+3 a)}>0 .
$$

At the symmetric equilibrium, Hotelling equilibrium price is:

$$
\begin{gathered}
\quad p^{*}=t+c\left(p^{*}, p^{*}, H^{*}\right)=t+F+\rho \sigma^{2}\left(\frac{1}{2}-H^{*}\right) \\
\Leftrightarrow \quad p^{*}-F=\left(1+\frac{1+2 a}{4 a(1+3 a)}\right) t
\end{gathered}
$$

Thus,

$$
\begin{aligned}
V(C, C) & =\frac{1}{2}\left(1+\frac{1+2 a}{4 a(1+3 a)}\right) t-\frac{\rho \sigma^{2}}{2}\left(\frac{1+2 a}{4 a(1+3 a)}\right)^{2} \\
& =\left(1+\frac{(1+2 a)(3+10 a)}{16 a(1+3 a)^{2}}\right) \frac{t}{2} .
\end{aligned}
$$

If both firms play Not Commit, they fully cover their exposure at $t=3$. 
Knowing this, they play at $t=2$ symmetric Hotelling game with constant marginal cost equal to the forward price. Thus,

$$
V(C, C)=\frac{t}{2}
$$

and

$$
V(C, C)-V(N C, N C)=\frac{(1+2 a)(3+10 a)}{16 a(1+3 a)^{2}} \frac{t}{2}>0 .
$$

D.3.2 Comparing $V(C, C)$ and $V(N C, C)$

Suppose again firm 2 plays $N C$, while firm 1 plays $C$. We prove that $V(N C, C)<$ $V(C, C)$. The equilibrium prices $\left(\bar{p}_{1}\left(H_{1}\right), \bar{p}_{2}\left(H_{1}\right)\right)$ are given by the Hotelling formula:

$$
\left\{\begin{array}{l}
\bar{p}_{1}=t+\frac{2\left(F+\rho \sigma^{2}\left(\frac{\bar{p}_{2}-\bar{p}_{1}}{2 t}+\frac{1}{2}-H_{1}\right)\right)+F}{3}=t+F+\frac{2 t}{3 a}\left(\frac{\bar{p}_{2}-\bar{p}_{1}}{2 t}+\frac{1}{2}-H_{1}\right) \\
\bar{p}_{2}=t+\frac{2 F+\left(F+\rho \sigma^{2}\left(\frac{\bar{p}_{2}-\bar{p}_{1}}{2 t}+\frac{1}{2}-H_{1}\right)\right)}{3}=t+F+\frac{t}{3 a}\left(\frac{\bar{p}_{2}-\bar{p}_{1}}{2 t}+\frac{1}{2}-H_{1}\right)
\end{array} .\right.
$$

Then,

$$
\bar{p}_{2}-\bar{p}_{1}=-\frac{t}{3 a}\left(\frac{\bar{p}_{2}-\bar{p}_{1}}{2 t}+\frac{1}{2}-H_{1}\right)=-2 t \frac{1}{1+6 a}\left(\frac{1}{2}-H_{1}\right)
$$

and

$$
D_{1}-H_{1}=\frac{\bar{p}_{2}-\bar{p}_{1}}{2 t}+\frac{1}{2}-H_{1}=\frac{6 a}{1+6 a}\left(\frac{1}{2}-H_{1}\right) .
$$

Thus,

$$
\left\{\begin{array}{l}
\bar{p}_{1}-F=\left(1+\frac{4}{1+6 a}\left(\frac{1}{2}-H_{1}\right)\right) t \\
\bar{p}_{2}-F=\left(1+\frac{2}{1+6 a}\left(\frac{1}{2}-H_{1}\right)\right) t
\end{array}\right.
$$

and

$$
\frac{\partial \bar{p}_{2}}{\partial H_{1}}=-\frac{2 t}{1+6 a}<0 .
$$

Maximization over $H_{1}$ yields:

$$
\frac{1}{2 t}\left(\bar{p}_{1}-F+\rho \sigma^{2}\left(H_{1}-D_{1}\right)\right) \frac{\partial \bar{p}_{2}}{\partial H_{1}}-\rho \sigma^{2}\left(H_{1}-D_{1}\right)=0
$$

$\Leftrightarrow$

$-\left(\left(1+\frac{4}{1+6 a}\left(\frac{1}{2}-\bar{H}_{1}\right)\right) t-\rho \sigma^{2} \frac{6 a}{1+6 a}\left(\frac{1}{2}-\bar{H}_{1}\right)\right) \frac{2 t}{1+6 a}+2 t \rho \sigma^{2} \frac{6 a}{1+6 a}\left(\frac{1}{2}-\bar{H}_{1}\right)=0$ 
$\Leftrightarrow$

$$
\frac{1}{2}-\bar{H}_{1}=\frac{1+6 a}{4(2+9 a)}
$$

Thus,

$$
\bar{p}_{2}-F=\left(1+\frac{1}{2(2+9 a)}\right) t
$$

and

$$
D_{2}\left(\bar{p}_{2}, \bar{p}_{1}\right)=\frac{1}{2}\left(1+\frac{1}{2(2+9 a)}\right),
$$

and

$$
V(N C, C)=\left(1+\frac{1}{2(2+9 a)}\right)^{2} \frac{t}{2} .
$$

Thus

$$
\begin{gathered}
V(C, C)>V_{2}(N C, C) \Longleftrightarrow 1+\frac{(1+2 a)(3+10 a)}{16 a(1+3 a)^{2}}>1+\frac{1}{2+9 a}+\frac{1}{4(2+9 a)^{2}} \\
\Longleftrightarrow \quad \frac{(1+2 a)(3+10 a)(2+9 a)^{2}}{36 a(1+4 a)(1+3 a)^{2}}>1
\end{gathered}
$$

which is verified numerically for all $a \geq 0$. 